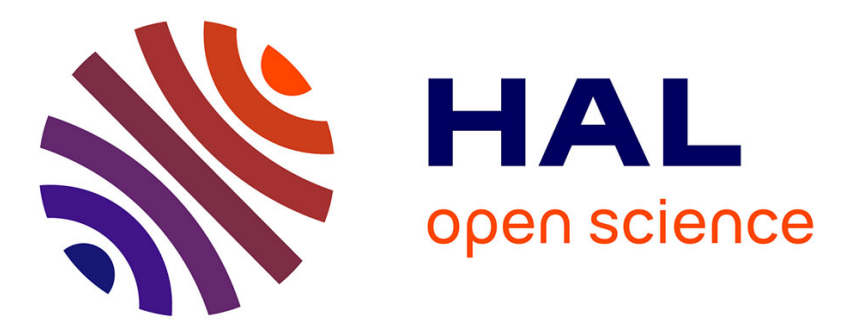

\title{
Response of the Antarctic Circumpolar Current to atmospheric variability
}

\author{
J.B. Sallee, R. Morrow, K. Speer
}

\section{To cite this version:}

J.B. Sallee, R. Morrow, K. Speer. Response of the Antarctic Circumpolar Current to atmospheric variability. Journal of Climate, 2008, 21 (12), pp.3020-3039. 10.1175/2007JCLI1702.1 • hal-00406819

\section{HAL Id: hal-00406819 \\ https://hal.science/hal-00406819}

Submitted on 10 Jun 2021

HAL is a multi-disciplinary open access archive for the deposit and dissemination of scientific research documents, whether they are published or not. The documents may come from teaching and research institutions in France or abroad, or from public or private research centers.
L'archive ouverte pluridisciplinaire HAL, est destinée au dépôt et à la diffusion de documents scientifiques de niveau recherche, publiés ou non, émanant des établissements d'enseignement et de recherche français ou étrangers, des laboratoires publics ou privés. 


\title{
Response of the Antarctic Circumpolar Current to Atmospheric Variability
}

\author{
J. B. SAllÉE \\ LEGOS, Toulouse, France \\ K. SPEER \\ Oceanography Department, The Florida State University, Tallahassee, Florida \\ R. MORROW \\ LEGOS, Toulouse, France
}

(Manuscript received 29 September 2006, in final form 11 October 2007)

\begin{abstract}
Historical hydrographic profiles, combined with recent Argo profiles, are used to obtain an estimate of the mean geostrophic circulation in the Southern Ocean. Thirteen years of altimetric sea level anomaly data are then added to reconstruct the time variable sea level, and this new dataset is analyzed to identify and monitor the position of the two main fronts of the Antarctic Circumpolar Current (ACC) during the period 1993-2005. The authors relate their movements to the two main atmospheric climate modes of the Southern Hemisphere: the Southern Annular Mode (SAM) and the El Niño-Southern Oscillation (ENSO). The study finds that although the fronts are steered by the bathymetry, which sets their mean pathway on first order, in flat-bottom areas the fronts are subject to large meandering because of mesoscale activity and atmospheric forcing. While the dominant mode of atmospheric variability in the Southern Hemisphere, SAM, is relatively symmetric, the oceanic response of the fronts is not, showing substantial regional differences. Around the circumpolar belt the fronts vary in latitude, exposing them to different Ekman transport anomalies induced by the SAM. Three typical scenarios occur in response to atmospheric forcing: poleward movement of the frontal structure in the Indian Basin during positive SAM events, an equatorward movement in the central Pacific, and an intensification without substantial meridional movement in the Indo-Pacific basin. The study also shows the geographical regions that are dominated by a SAM or ENSO response at low and high frequencies.
\end{abstract}

\section{Introduction}

Atmospheric studies in the Southern Hemisphere have shown a strong dominance of one particular mode of variability that accounts for most of the variance in sea level pressure (SLP; Thompson and Wallace 2000). The ringlike character of this mode (see Fig. 1a) has given rise to the term "Southern Annular Mode" (SAM). There is a clear out-of-phase pressure relationship over the polar and subtropical regions. Thompson and Wallace (2000) showed that this ringlike pattern is associated with a typical zonal wind pattern. During positive SAM periods, the maximum wind stress is shifted to the south, and the westerly winds are rein-

Corresponding author address: J. B. Sallée, LEGOS, 14 Avenue Edouard Belin, Toulouse 31400, France.

E-mail: sallee@legos.cnes.fr forced around $60^{\circ} \mathrm{S}$ with easterly anomalies around $35^{\circ} \mathrm{S}$. The Antarctic Circumpolar Current (ACC) is strongly wind forced, although whether or not its forcing is dominated by the wind stress or the wind stress curl remains controversial (e.g., Baker 1982; Warren et al. 1996; Hughes et al. 1999; Gille et al. 2001; Dong et al. 2006). However, it may be expected to move in response to a changing SAM. Coupled model studies have suggested that a dominantly zonally symmetric response to the SAM exists in the Southern Ocean (Hall and Visbeck 2002; Sen Gupta and England 2006).

Other climate modes can also impact the Southern Ocean circulation. The El Niño-Southern Oscillation (ENSO), defined by sea surface temperature (SST) anomalies in the tropical Pacific latitudes, has a definite zonally asymmetric impact on the atmospheric circulation at extratropical latitudes. ENSO generates atmospheric Rossby waves that travel to high latitudes 


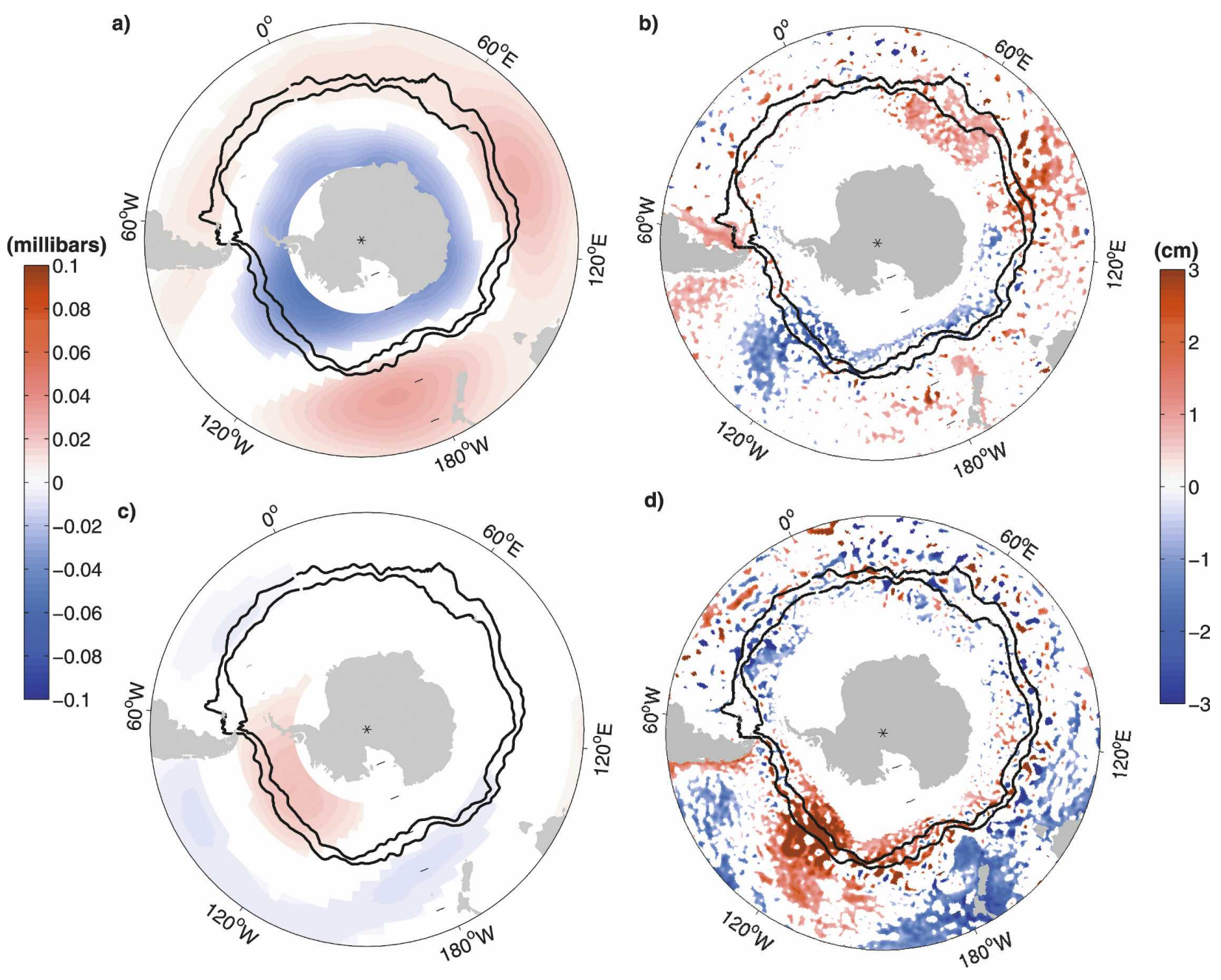

FIG. 1. (a) SLP and (b) SLA regressed onto the SAM index for the period 1993-2005. (c) SLP and (d) SLA regressed onto the ENSO index for the period 1993-2005. Patterns below the 80\% significance limit are blanked. The black lines show the mean SAF and PF positions.

(Hoskins and Karoly 1981; Turner 2004). Karoly (1989) demonstrated that El Niño (positive ENSO) events are associated with the generation of two large low pressure cells over South America and New Zealand, and one high pressure cell over the central Pacific. This pattern, clearly shown by a regression of SLP on the ENSO index (see Fig. 1c), is known as the PacificSouth American (PSA) Oscillation. This mode is centered on the Pacific Ocean and is associated with the second emprical orthogonal function (EOF) mode of the SLP field in the Southern Hemisphere (SAM being the first mode).

With respect to the mean ocean circulation, the Southern Ocean is distinguished from all other oceans by the presence of a strong eastward, circumpolar current, the Antarctic Circumpolar Current. The ACC connects the three major ocean basins (Atlantic, Pa- cific, and Indian) and redistributes active and passive oceanic tracers such as heat, salt, and nutrients. Thus, anomalies created by atmospheric forcing in one basin can be carried around the globe affecting the global oceanic mass balance, ocean stratification, circulation, and consequently heat transport and climate. The ACC is traditionally thought to be composed of a series of hydrographic fronts, associated with sloping isopycnals and relatively strong meridional property gradients. Several cores of strong horizontal gradients in potential temperature, salinity, and density, implying intense geostrophic currents, typically characterize the ACC fronts (Deacon 1937; Nowlin et al. 1977; Orsi et al. 1995; Belkin and Gordon 1996). These fronts separate regions with different water masses and more homogeneous oceanic properties.

The fronts are usually defined by simple criteria 
based on the interior hydrographic structure (e.g., Peterson and Stramma 1991; Orsi et al. 1995; Belkin and Gordon 1996). Recently, however, satellite data have provided a new set of frontal definitions based on gradients of sea surface temperature or sea surface height (SSH; Gille 1994; Hughes and Ash 2001; Sokolov and Rintoul 2002, 2008; Dong et al. 2006). Interestingly, the two types of frontal definitions, based on interior hydrographic structure or on surface satellite data, show close agreement in regional comparisons (Sokolov and Rintoul 2002, 2008; Dong et al. 2006). However, the satellite observations not only reveal the time variability of these fronts but also show that the ACC has a much more complex frontal structure than is evident from climatological hydrographic data.

Previous work on the ocean response to the different atmospheric modes has mainly been based on numerical modeling results (e.g., Hall and Visbeck 2002; Sen Gupta and England 2006). These numerical results are difficult to confirm with real ocean observations because of the lack of data from the mid- to high latitudes in the Southern Ocean. Gridded altimetric sea level data offer relatively uniform spatial coverage at roughly $100-\mathrm{km}$ scales every week for more than $13 \mathrm{yr}$, permitting studies of the lower- frequency variability. In addition, as of 2006, the international Argo project has added more than 30000 hydrographic profiles in the Southern Ocean, coarsely distributed in space, but evenly distributed in time, providing an unprecedented seasonal sampling of the subsurface ocean.

Based on these two databases, altimetry and Argo, we are now able have a better view of the Southern Ocean at the circumpolar scale. A first glance reveals that the ocean does not respond to the SAM atmospheric forcing as a purely zonal response. Figure $1 \mathrm{~b}$ shows that the altimetric Sea Level Anomaly (SLA) regressed onto the SAM index between 1993 and 2005 has distinct regional differences, although the SAM shows an annular pattern during the same period (Fig. 1a). In particular, in the Indian sector from $30^{\circ}$ to $120^{\circ} \mathrm{E}$, the sea level is anticorrelated with the surface pressure (Figs. 1a,b). Sea level anomalies regressed onto the ENSO index are well correlated with surface pressure in the Pacific (Figs. 1c,d). In other basins, the ENSO sea level response does not resemble the ENSOrelated winds, but tends to be anticorrelated with the oceanic SAM response (Figs. 1b,d).

In this paper we are interested in how changes in the large-scale atmospheric forcing can impact the Southern Ocean circulation and fronts. For example, trends in the atmospheric circulation are thought to have modified the Pacific subtropical gyre (Roemmich et al. 2007; Qiu 2002; Vivier et al. 2005). This study will con- sider the Southern Ocean response to the primary atmospheric modes. We will focus on the frontal zones because they will be associated with the strongest signals of variability in SST, intensity of the flow, and upwelling.

We will present a robust satellite-based definition of the two main dynamic fronts in the Southern Ocean: the Subantarctic Front (SAF) and the Polar Front (PF; section 2). These two fronts carry up to $75 \%$ of the total ACC transport south of Australia (Rintoul and Sokolov 2001). In certain regions of the ACC, these fronts are strongly constrained by the bathymetry (Moore et al. 1999; Dong et al. 2006), but elsewhere the frontal positions vary regionally in response to the main climate modes (ENSO and SAM; section 3). In section 4 , we will discuss the mechanisms that control the frontal movement for the different basins.

\section{Data and methods}

\section{a. Data}

\section{1) Mean sea surface height}

In this study, the vertical structure of the Southern Ocean is determined from the combination of two distinct datasets: the Argo database and the World Ocean Circulation Experiment (WOCE) Southern Ocean database (SODB).

The Argo international program has seeded all of the world's oceans since 1999 and is particularly important in the Southern Ocean, which is historically poorly sampled. As of 2006, this database includes about 30 , 000 Southern Ocean profiles. These data were collected and made freely available by the international Argo project and the national programs that contribute to it (http://www.argo.ucsd.edu; http://www.ifremer.fr/ coriolis/cdc/argo.htm).

We only use profiles that have passed the Argo realtime quality control, containing information on their position, date, temperature $(T)$, and salinity $(S)$ profiles. Most Argo profiles sample $T$ and $S$ from the surface to a 2000-m depth every 10 days.

The SODB consists of about 93, 000 hydrographic [bottle and conductivity-temperature-depth (CTD)] stations south of $25^{\circ} \mathrm{S}$. The primary source is the World Ocean Atlas 98 (WOA98) and its successor, World Ocean Database 2001 (WOD01), which have been augmented with the WOCE observations and also with stations coming directly from investigators. Each station was individually quality controlled by comparison to nearby WOCE stations. This work of collection and quality control has been performed and made freely 

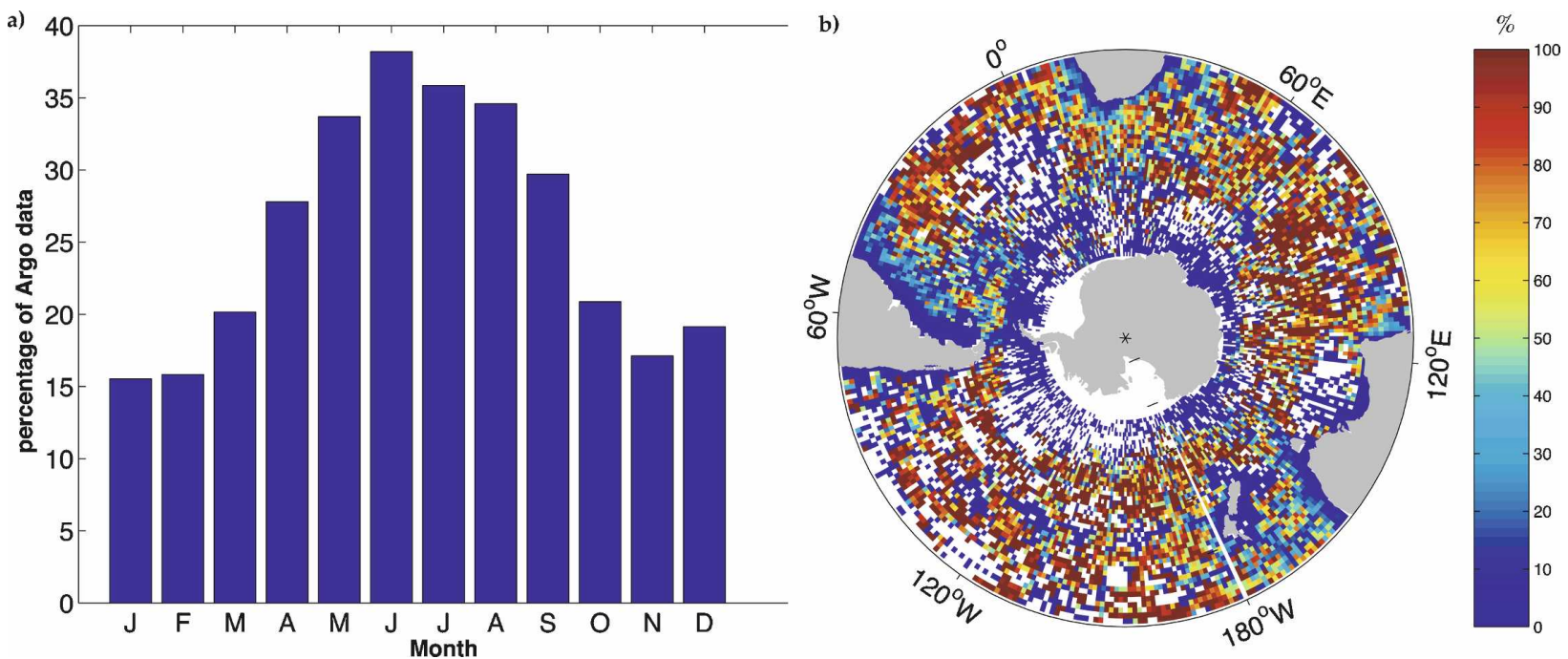

FIG. 2. (a) Monthly and (b) spatial in $1^{\circ}$ bins' percentage of Argo profiles in the combined Argo-SODB database, gridded from $1^{\circ}$ bins.

available (see http://woceSOatlas.tamu.edu for more information).

The Argo project contributes about $30 \%$ of the total number of Southern Ocean profiles; however, it provides very important sampling. In fact, the two datasets are complementary in space and time. The first $5 \mathrm{yr}$ of Argo sampling provides more profiles in the center of ocean basins and during austral winter and spring than in decades of historical data (see Fig. 2).

Our first goal was to establish the long-term mean dynamic height field and geostrophic circulation of the Southern Ocean from the Argo and SODB hydrography. We selected the $T-S$ profiles defined between 10 and $1500 \mathrm{~m}$ to produce a database of the surface dynamic height referenced to $1500 \mathrm{~m}$. This $1500-\mathrm{m}$ reference level was chosen as the best compromise between the deepest possible level and including a maximum number of data profiles. In this database, the percentage of Argo profiles is even more striking, providing 22894 profiles (55\%) against 18956 profiles (45\%) for the SODB. We computed mean dynamic height and geostrophic circulation maps using the Ridgway et al. (2002) interpolation method.

\section{2) Time variable sea surface height}

To map the time-variable dynamic height and monitor the frontal positions, we have constructed $13 \mathrm{yr}$ of weekly maps of sea surface height referenced to $1500 \mathrm{~m}$ $\left(\mathrm{SSH}_{1500 \mathrm{~m}}\right)$ from 1993 to 2005 . Specifically, we add the mean dynamic height computed from the historical database [see section 2a(1)] to the weekly maps of altimetric sea level anomaly. The mapped SLA fields are provided by Collecte, Localisation, Satellites (CLS)/ Archiving, Validation, and Interpretation of Satellite Oceanographic data (AVISO) and are based on data from the available altimeter missions [Ocean Topography Experiment (TOPEX)/Poseidon, European Remote Sensing Satellites (ERS-1 and -2), Geosat FollowOn (GFO), Envisat, and Jason). The mapping technique is described by LeTraon et al. (1998). Anomalies are calculated with respect to a 7-yr mean (1992-99) and are mapped onto a $1 / 3^{\circ}$ grid in longitude and a variable grid in latitude, ranging from approximately $1 / 20^{\circ}$ at $80^{\circ} \mathrm{S}$ to $1 / 4^{\circ}$ at $30^{\circ} \mathrm{S}$. A discussion of the aliased high-frequency errors is given by Morrow et al. (2003). The altimetry data resolves wavelengths greater than $150 \mathrm{~km}$, with a temporal resolution of 20 days (Ducet et al. 2000). In the Southern Ocean where the ground tracks converge, we can resolve $100-\mathrm{km}$ wavelengths. These weekly data are filtered to a 1-month interval to compare them to the monthly atmospheric indexes used in this study.

\section{3) Climatic indexes}

The monthly Southern Annular Mode Index and the El Nino-Southern Oscillation index were obtained from the National Oceanic and Atmospheric Administration (NOAA)/Climate Prediction Center Web site (www.cpc.ncep.noaa.gov) for the period 1979-2004. The SAM index is defined as the first principal component of monthly 700-hPa geopotential height anomalies from the National Centers for Environmental Prediction-National Center for Atmospheric Research (NCEP-NCAR) reanalysis dataset. We use the Niño3.4 ENSO index. Its variations are based on SST 
anomalies averaged over the region spanning $5^{\circ} \mathrm{N}-5^{\circ} \mathrm{S}$, $170^{\circ}-120^{\circ} \mathrm{W}$.

\section{4) Atmospheric data}

To investigate the link between the atmospheric and oceanic dynamics, we use the monthly NCEP reanalysis of wind stress and sea level pressure (SLP), which are made available by the NOAA-CIRES Climate Diagnostic Center (CDC; http://www.cdc.noaa.gov).

\section{b. Definition of the fronts in the ACC}

Recently, new Southern Ocean frontal definitions have emerged based on satellite data (Gille 1994; Hughes and Ash 2001; Sokolov and Rintoul 2002, 2008; Dong et al. 2006). Sokolov and Rintoul (2002) found that a judicious choice of SSH contour provided a good representation of the mean position of the main fronts south of Tasmania, and more recently they developed an objective method to select the SSH contours representing different fronts (Sokolov and Rintoul 2008). In the region between $100^{\circ} \mathrm{E}$ and $180^{\circ}$, they found a series of contour values that was relatively stable in time and space. They concluded that 10 branches are necessary to completely describe the ACC in this region. The primary frontal positions appear to agree well with the previous hydrographic-based definitions.

The strong advantage of the satellite definition is the potential for revealing the complexity and the variability of the fronts. Fronts merge, split, weaken, meander, and so on, and this variability can be monitored with satellite data. In comparison, hydrographic data provide information on the vertical structure of the fronts. However, given that the in situ data distribution is sparse, a description based on nonsynoptic hydrographic data tends to mix together the different frontal states.

We chose to apply a similar SSH contour definition to describe the two most energetic fronts of the Southern Ocean, the Subantarctic Front and Polar Front. In the presence of time variations in intensity, splitting, and merging of fronts, we cannot expect even the primary fronts to be uniquely defined or identified by a single contour or by any other quantity at every time. They can be ambiguous at certain times within their zone of strong amplitude variability. However, a single contour can be associated with the front in the sense that most of the time (for instance, $98 \%$ in the case of the PF, see below) they would be located together based on a suite of traditional definitions. Because fronts are an association of filaments that merge, split, appear, and disappear within the primary frontal zones (Hughes and Ash 2001), the motion of a single contour does not necessarily always follow exactly the same fila- ment of a given front. However, as we will see, it will often follow the filament with a strong SSH gradient.

Gradients of SSH or SST are a natural way to define a front. To exploit an SSH gradient definition, one would have to find the location of the maximum gradients and define a curve going through these points. The choice of the contour value has to be carefully defined to match the subsurface data as well as the position of the maximum $\mathrm{SSH}$ gradient.

The traditional definition of the Polar Front is the northern limit of the Antarctic Winter Water (AAWW) defined as the tongue of $2^{\circ} \mathrm{C}$ water at $200 \mathrm{~m}$ (Orsi et al. 1995; Belkin and Gordon 1996). Our choice of contour that defines this limit is $\mathrm{SSH}_{1500 \mathrm{~m}}=0.95 \mathrm{~m}$, which shows very good agreement with the subsurface definition of the AAWW tongue. Figure 3 shows the distribution of historical profiles (from SODB and Argo) sampled during the altimetric period, with respect to the AAWW position. Almost every profile with AAWW characteristics ( $T$ less than $2^{\circ} \mathrm{C}$ within the first $200 \mathrm{~m}$ ) has an SSH referenced to $1500 \mathrm{~m}$, which is less than $0.95 \mathrm{~m}(99.4 \%)$. Conversely, almost every profile found north of the AAWW has an SSH referenced to $1500 \mathrm{~m}$ greater than $0.95 \mathrm{~m}(98 \%)$. The contour $\mathrm{SSH}_{1500 \mathrm{~m}}=0.95 \mathrm{~m}$ was chosen because it maximizes these percentages.

The Subantarctic Front can be defined as the maximum in the meridional gradient of temperature, density, or potential vorticity (PV). Belkin and Gordon (1996) define the SAF as the maximum temperature gradient at $300 \mathrm{~m}\left(T_{300 \mathrm{~m}}\right)$. Unfortunately, we cannot directly compare this definition with our altimetric definition because the sampling of historical profiles is sparse and we cannot accurately resolve the horizontal property gradients. Instead, we have extracted $T_{300 \mathrm{~m}}$ from profiles obtained during the altimetric period and calculated their distance from the $\mathrm{SSH}_{1500 \mathrm{~m}}=1.20-\mathrm{m}$ contour for the same day. We observe that the $\mathrm{SSH}_{1500 \mathrm{~m}}=$ $1.20-\mathrm{m}$ contour coincides with the region where there is a sharp change in $T_{300 \mathrm{~m}}$ along the ACC pathway, and also agrees very well with the maximum in potential vorticity gradient along the $\sigma_{\theta}=27 \mathrm{~kg} \mathrm{~m}^{-3}$ (see Fig. 4). We tested different contour values and found that $1.20 \mathrm{~m}$ was associated with the strongest gradients of $T_{300 \mathrm{~m}}$ and $\mathrm{PV}_{27 \mathrm{~kg} \mathrm{~m}^{-3} \text {. }}$

Downstream of Drake Passage, the fronts cross the Falkland Ridge and make a loop to the north along the Argentina coast to join the Brazil Current (Orsi et al. 1995). The individual SSH contours do track this pathway quite well, but our mean and variability calculations use longitudinal bin averages that create a false mean position and exaggerate the variability in the loop area. These statistical errors are increased when the 

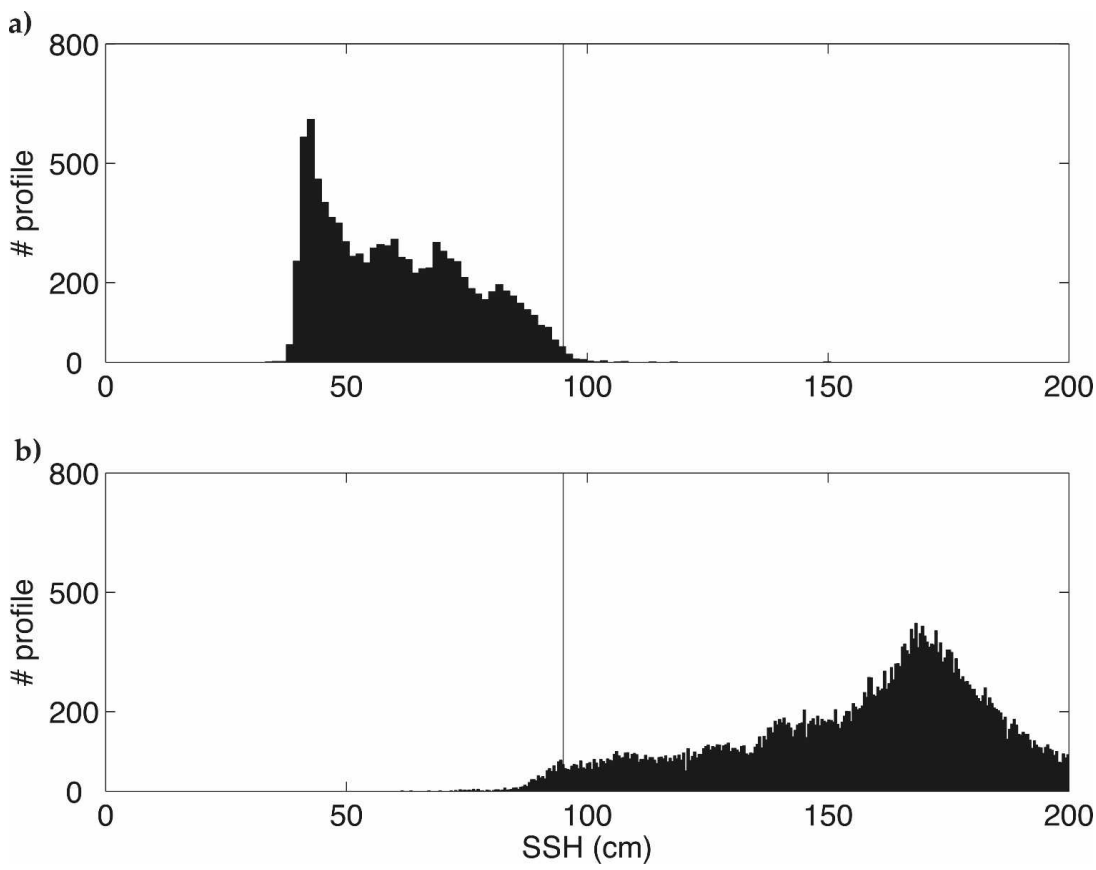

FIG. 3. (a) Number of profiles sampled within the AAWW region as a function of the $\mathrm{SSH}_{1500}$ of the profile. (b) Number of profiles sampled outside the AAWW region as a function of the $\mathrm{SSH}_{1500}$ of the profile. The vertical line represents $\mathrm{SSH}_{1500}=0.95 \mathrm{~m}$, our chosen PF contour.

loop is not connected: for example, when the jet path switches south of the Falkland Islands. For these reasons, this area from $290^{\circ}$ to $310^{\circ} \mathrm{E}$ will not be analyzed further in this study.

Figure 5 shows the mean position of the PF and SAF, as defined from the $0.95-\mathrm{m}$ and $1.20-\mathrm{m}$ contours of $\mathrm{SSH}_{1500 \mathrm{~m}}$, overlaid on the climatological SST and SSH gradients. Our chosen contours join the patches of strong gradients, which are characteristic of the intense jet. The exception is in the region $20^{\circ}-70^{\circ} \mathrm{E}$ where the strongest gradients are associated with the Agulhas Retroflection and its fronts. We have compared our frontal definition with the Sokolov and Rintoul (2008) fronts defined for the region $100^{\circ} \mathrm{E}-180^{\circ}$. Sokolov and Rintoul (2008) have different frontal contour values because they use a climatological steric height relative to $2500 \mathrm{~m}$. To include the Argo floats, our climatology is relative to $1500 \mathrm{~m}$, so we can't directly compare our contour values. However, we can compare the positions of our respective fronts. Our PF corresponds to their northern branch of the PF, which is the most intense of their three PF branches; our SAF corresponds to their southern branch of the SAF, which is again their most intense branch. Thus, with our definition, we have identified the most intense fronts of the ACC in the zone $100^{\circ} \mathrm{E}-180^{\circ}$.

Our mean frontal positions agree globally with the mean position of Orsi et al. (1995) (see Fig. 6). How- ever, in some places, large differences exist. For example, near the Kerguelen Plateau our method sometimes positions the PF to the south of Kerguelen Island and sometimes to the north. Orsi et al. (1995) located the PF farther north. Other studies have also positioned the PF clearly north of the island (e.g., Gille 1994; Belkin and Gordon 1996; Dong et al. 2006). However, our position seems to be consistent with the results of Moore et al. (1999), Kostianoy et al. (2004), and Park et al. (1998). Faced with this controversial positioning of the front in this region, we tested our front definition against the repeated Ocean Indien Service d'Observation (OISO) CTD sections for the $3 \mathrm{yr}$ from 1998 to 2001 (see Fig. 7). Our PF is coherent with the subsurface AAWW tongue extension over these three summers, which gives us confidence that our PF contour is consistently following the primary PF location. The SAF is also coherent with the subsurface data.

It is also instructive to consider the time series of frontal movements at a given location. Figure 8a shows the time series of our SAF and PF contours, superimposed on the meridional SSH gradients at $255^{\circ} \mathrm{E}$ in the southeast Pacific. This deep-basin region with relatively weak mean gradients (Fig. 5) is also a region where our mean fronts show different stationary meanders compared to the Orsi fronts (Fig. 6). Figure 8a shows that both the PF and the SAF track coherent positive $\mathrm{SSH}$ 

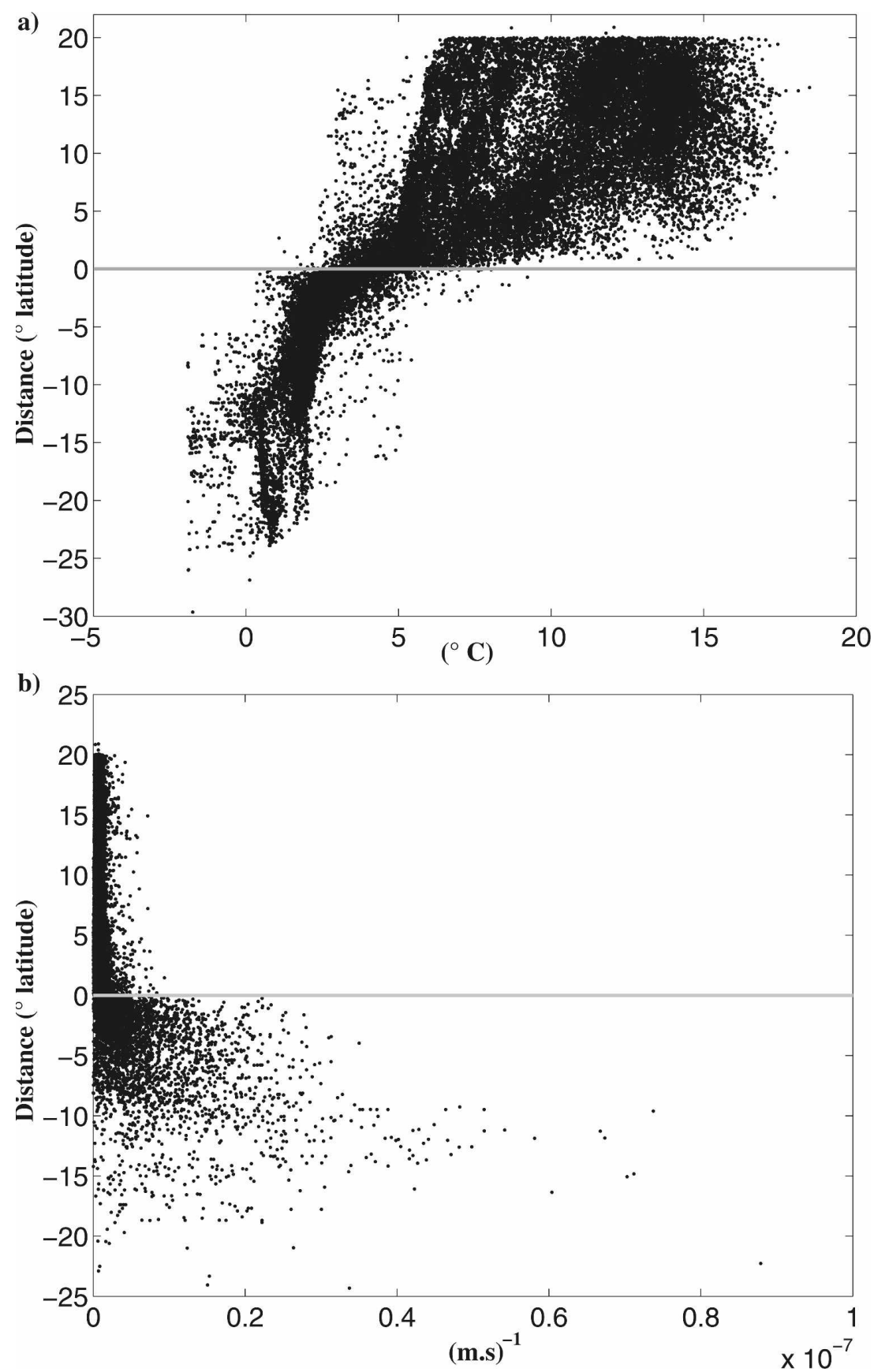

FIG. 4. (a) Distance ( ${ }^{\circ}$ latitude) of $\mathrm{SSH}_{1500}$ from the 1.20 -m contour for each profile, plotted as a function of $T_{300 \mathrm{~m}}$. (b) Distance of $\mathrm{SSH}_{1500}$ from the $1.20 \mathrm{-m}$ contour as a function of the PV on $\sigma_{\theta}=27 \mathrm{~kg} \mathrm{~m}^{-3}$. Positive distance corresponds to a profile north of the contour; negative distance corresponds to a profile south of the contour. The contour $1.20 \mathrm{~m}$ is our chosen SAF contour.

gradient structures over time. Furthermore, there are clearly periods in which the fronts split (e.g., around year 2002), and our chosen contour tends to follow the most intense branch. There are a few high- frequency outliers, but these events are rare. In general, the varying position of the maximum SSH gradient is very well captured by our chosen $1.2-$ and $0.95-\mathrm{m}$ contours. The method provides one way to analyze the evolution of the complex frontal structure that is associated with the two primary fronts of the ACC.

It is not too surprising that fronts defined by the contour method are in good agreement with the sub- 

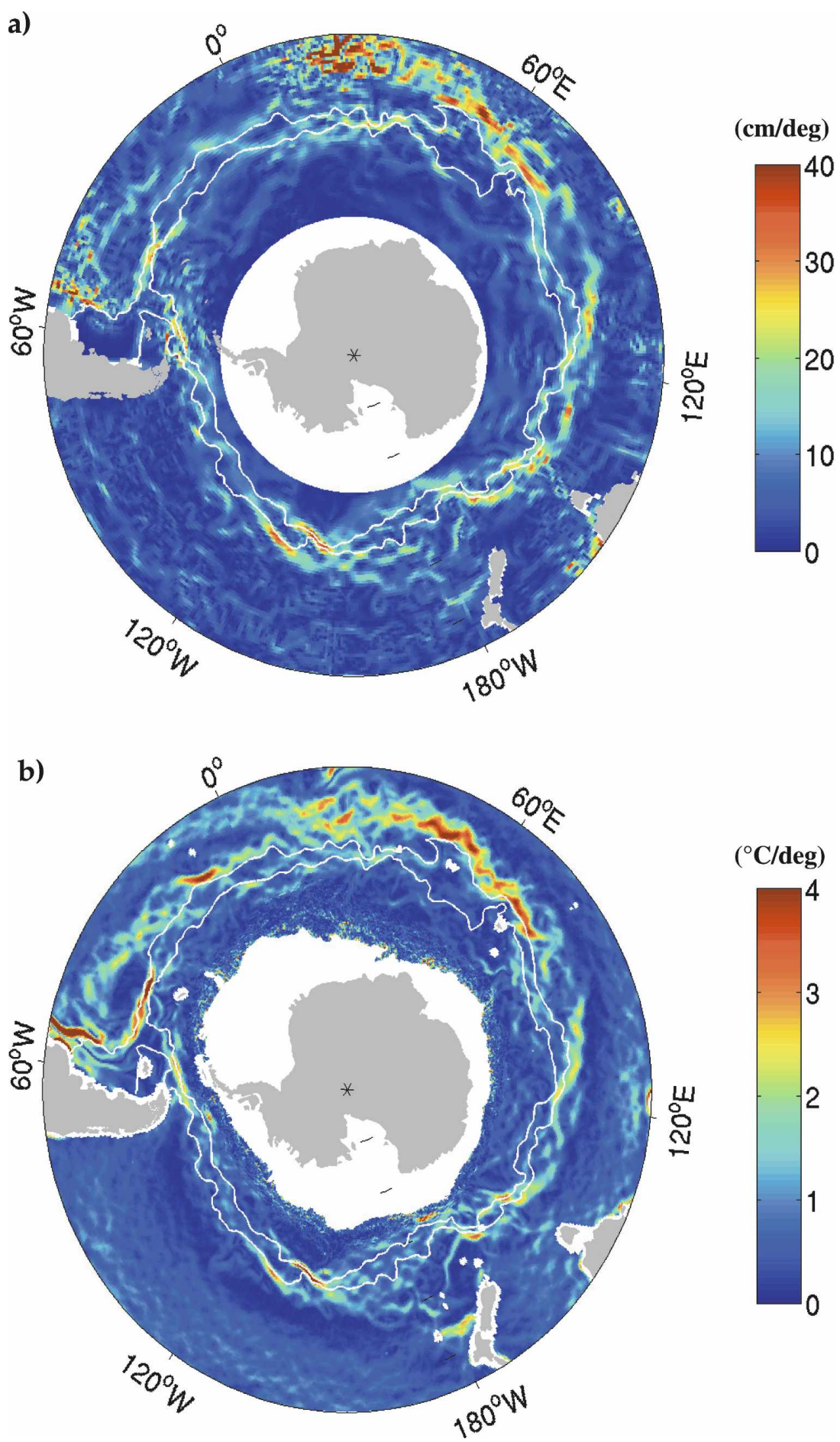

FIG. 5. Mean (a) SSH gradient and(b) SST gradient. White lines are the mean positions of SAF (north) and PF (south) from the climatological SSH field.

surface hydrography. In the Southern Ocean, and particularly for the SAF, the baroclinicity extends to the seafloor. The geopotential height of the sea surface is approximately a streamline and exhibits a tight empiri- cal relationship with the hydrographic structure of the entire water column (Sun and Watts 2001; Watts et al. 2001). Hence, the maximum in SSH gradient (associated with the core of the internal jet) is associated with 


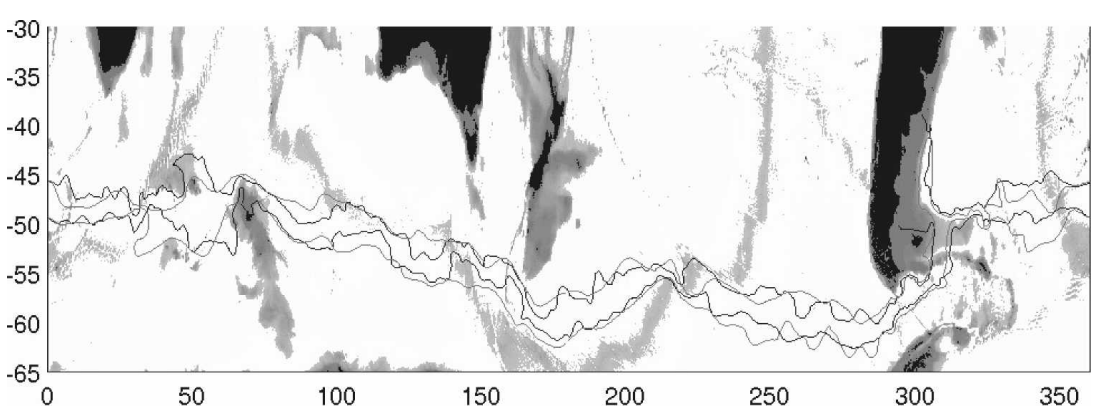

FIG. 6. Mean PF (south) and SAF (north) positions from Orsi et al. (1995; gray) and our SSH contour method (black), superimposed on the bathymetry shallower than $3000 \mathrm{~m}$.

a particular hydrographic structure and will also be associated with a particular SSH contour. This is why an SSH contour provides an accurate estimate of the position of the principal jet cores in the ACC, for the combined mean and mesoscale variability.
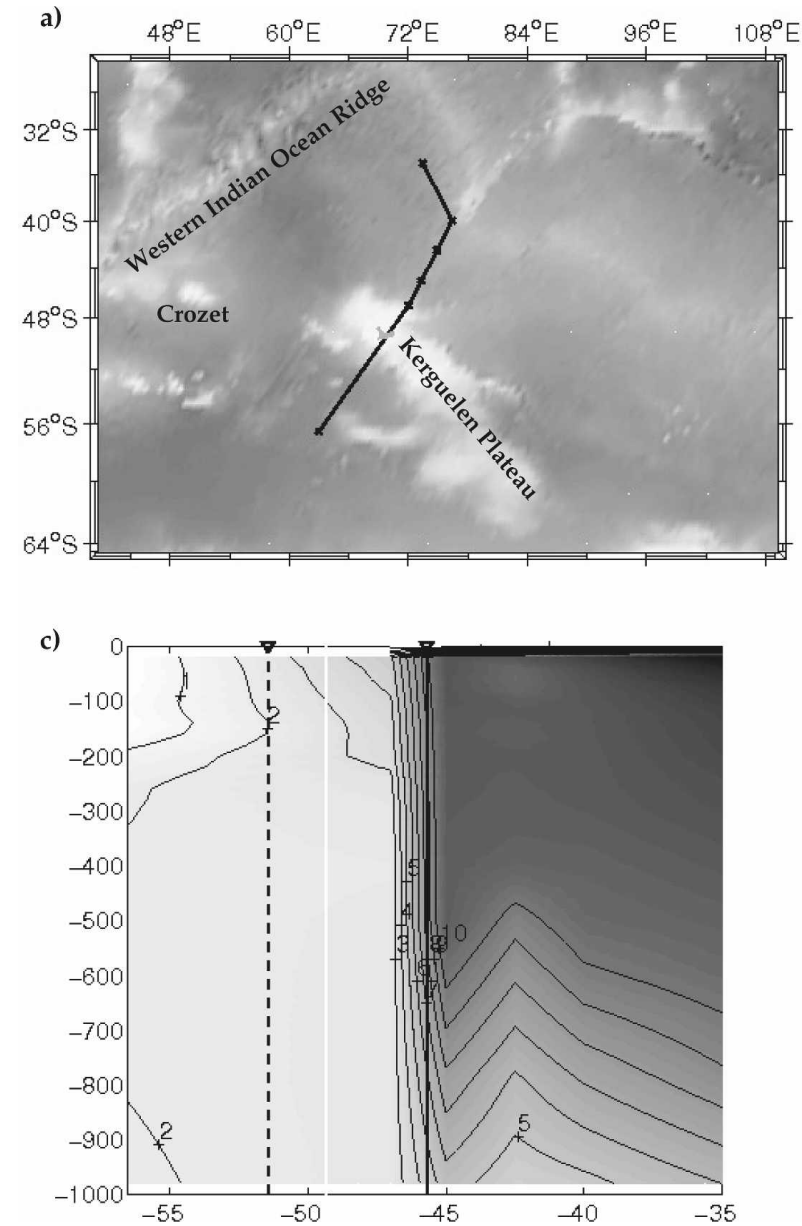

\section{c. Errors in the frontal definition}

This validation in different regions supports the notion that associating an SSH contour with a particular front is realistic and gives us confidence to continue b)

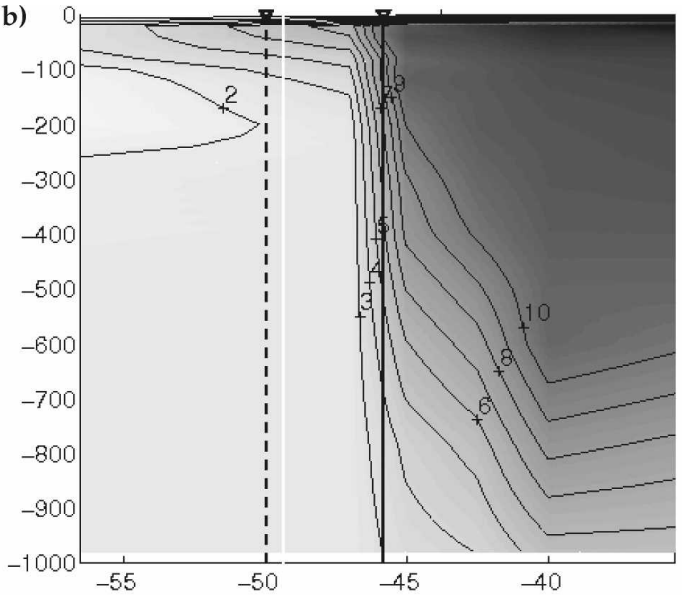

d)

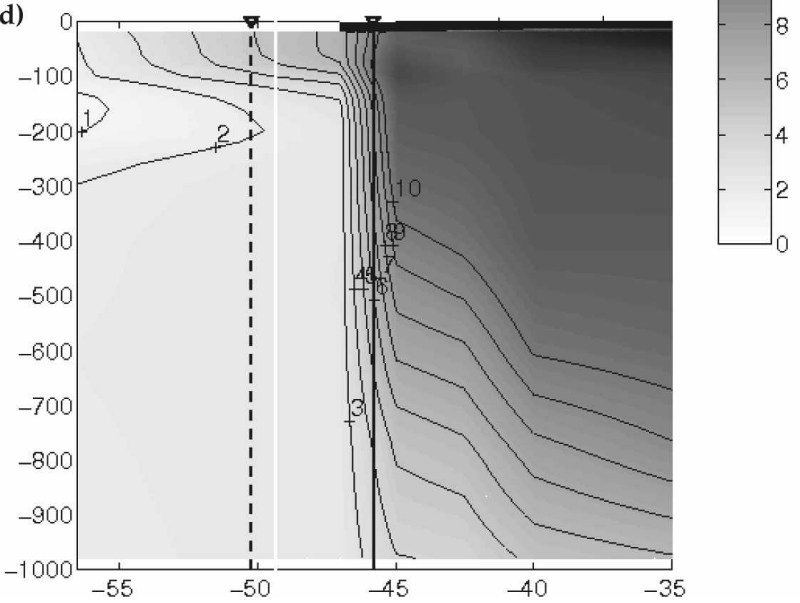

FIG. 7. Vertical temperature sections from the repeated OISO sections in the southern Indian Ocean from 1998 to 2001. (a) Section positions; summer sections in (b) 1997/98, (c) 1998/99, and (d) 1999/2000. The vertical solid black line represents the position of the SAF found by the SSH contour method at the period of the cruise; the vertical dashed black line is the PF position found by the contour method; and the white line represents the position of Kerguelen Island. 
a)

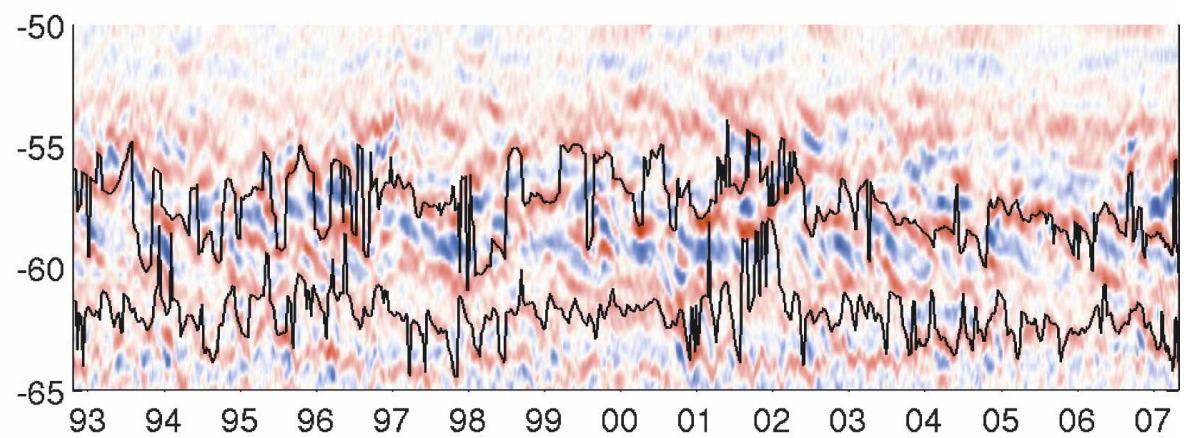

b)

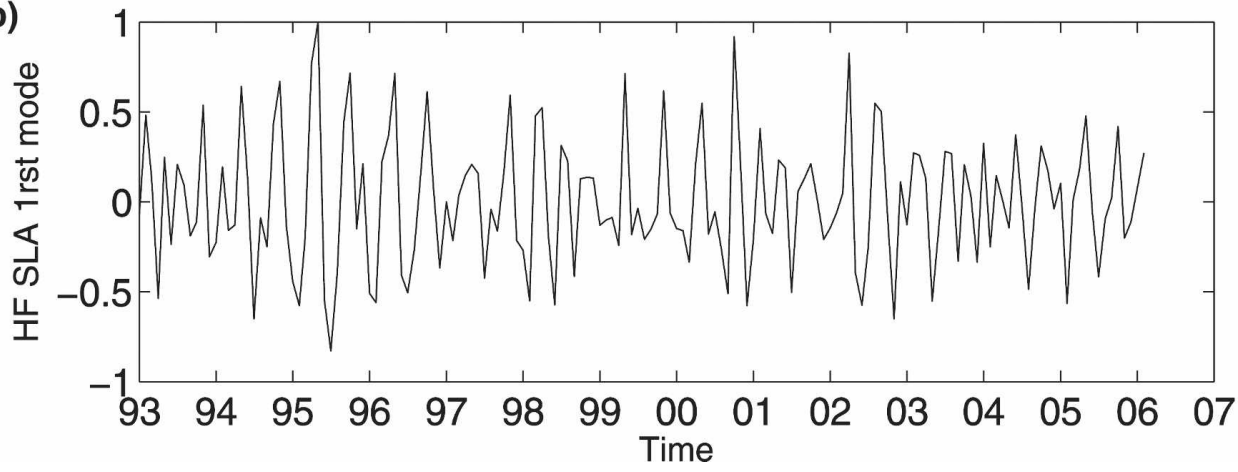

FIG. 8. (a) Hovmöller diagram of our SAF and PF contours, superimposed on the meridional SSH gradients at $255^{\circ} \mathrm{E}$ in the southeast Pacific. Positive gradient values are shown in red and negative in blue. The $x$ axis is the time in year. (b) Normalized time series of the first EOF of the large-scale, high-frequency SLA mode. The spatial mode is similar to the high-frequency barotropic modes found in previous studies (e.g., Fukumori et al. 1998) and is at maximum in the southeast Pacific around $255^{\circ} \mathrm{E}$. Also at $255^{\circ} \mathrm{E}$, this mode introduces maximum variations of $\pm 1^{\circ}$ latitude in the frontal position.

with a study on frontal variability. However, we need to address the errors of this method. Note that the inverse barometer effect has already been corrected in the treatment of altimetric data (Ducet et al. 2000); hence it does not represent an error on the contour position. The main errors can be induced by

- the seasonal steric cycle,

- the trend in long-term sea level rise,

- using a $1500-\mathrm{m}$ level of no motion,

- the accuracy of the altimeter data, and

- large-scale, high-frequency SSH variability.

We examine these in turn. Stammer (1997) estimated the seasonal steric cycle in the global ocean and found it to be less than $2 \mathrm{~cm}$ in the Southern Ocean. Lombard et al. (2006) found an increasing trend in long-term sea level of around $3 \mathrm{~mm} \mathrm{yr}^{-1}$ on average in the Southern Ocean from 1993 to 2003. Over a decade, this gives a large-scale sea level rise of about $3 \mathrm{~cm}$, which tends to shift our frontal positions south over the same period.

Using a 1500-m level of zero motion implies that we neglect the mean barotropic flow and the mean baroclinic flow below $1500 \mathrm{~m}$. To assess the impact of this assumption, we compared our mean dynamic height field with the absolute mean dynamic height product developed by Rio et al. (2005). This latter product mixes satellite data from GRACE and altimetry with in situ data from SVP drifters, Argo profiles, and shipbased hydrographic data. Their mean field includes both barotropic and baroclinic components and is in very good agreement with ours. The Rio et al. (2005) product uses a different reference density; when using the Rio et al. (2005) mean SSH, our PF corresponds to a $0.6-\mathrm{m}$ contour and our SAF to a $1.0-\mathrm{m}$ contour. We find that both products show the same large-scale patterns and large stationary meanders of the ACC. Using the 1500-m level-of-zero motion will reduce the steric height amplitude and slightly reduce the intensity of the cross-frontal gradients. However, it does not affect the position of the mean dynamical structure of the ACC fronts. We note that the variable part of the barotropic and the deep baroclinic flow will be observed by altimetry. The Rio et al. (2005) product does not use in situ profiles sampled after 2002. Given the substantial increase in the number of Argo profiles in the Southern Ocean since 2002, we believe our mean field provides a 
better representation of the finer-scale structure of the Southern Ocean.

The accuracy of the altimeter data is another source of error for our method. It includes many different kinds of errors (Ducet et al. 2000), in particular, the high-frequency barotropic variability in the Southern Ocean, although this is partly corrected by the mapping technique (LeTraon et al. 1998). We estimate the altimetric sea level error to be less than $3 \mathrm{~cm}$, based on Ducet et al. (2000).

Any kind of large-scale sea level variation centered on the front will add a bias that moves the SSH contour position without necessarily shifting the maximum in SSH gradient. This will induce an error in our front position, which will no longer be consistent with the core of the jet (or the maximum in $\mathrm{SSH}$ gradient). As we have seen above, the long-term sea level trend is one large-scale pattern that can induce such a problem. Another pattern is the large-scale barotropic sea level response to atmospheric forcing that has a strong amplitude in the Southern Ocean. Coherent patterns of sea level variability with spatial scales of $1000 \mathrm{~km}$ and time scales of 20 days to $1 \mathrm{yr}$ have been found in the South Indian Basin and South Pacific basin (Fukumori et al. 1998; Webb and de Cuevas 2002; Fu 2003). To assess the effect of such variability on our frontal movements, we performed an EOF analysis on the SLA field filtered over these time and space scales. The first EOF mode has a similar pattern as that found by Fukumori et al. (1998). The EOF mode is revealed by spatial filtering the SLA field over areas much larger than the fronts (larger than $1000 \mathrm{~km}$ ), and it is associated with $10 \%$ of the variance. Without the spatial filtering, the variance of this apparent barotropic mode vanishes. The amplitude of this mode is approximately $4 \mathrm{~cm}$ in the most variable areas (South Indian Basin and South Pacific basin). However, the frontal displacements associated with this EOF mode are weak around the circumpolar belt, with a circumpolar average of $0.1^{\circ} \pm 0.2^{\circ}$ for the SAF, and $0.15^{\circ} \pm 0.2^{\circ}$ for the PF. An exception is in the South Pacific where the barotropic mode is strong and can introduce frontal movements of up to $1^{\circ}$ latitude. However, even here, our time series example at $255^{\circ} \mathrm{E}$ in the South Pacific shows that our frontal movements do follow the maximum SSH gradients (Fig. 8a) and that these frontal movements are not correlated ( $r=0.1$ for both $\mathrm{PF}$ and SAF) with the first EOF (Fig. 8b). This high-frequency mode may be responsible for the high-frequency noise in our contour positions, but it is not the dominant mechanism controlling the observed frontal movements.

All of these different contributions will induce move- ments in the SSH contour, but do not represent a movement of the jet core, and are thus considered errors of the method. The sum of these errors for the contour method is $\pm 12 \mathrm{~cm}$, which corresponds to $\pm 1.2^{\circ}$ of error in the latitudinal position.

\section{Frontal variability in the $\mathrm{ACC}$}

\section{a. Overview of variability}

The Polar Front and Subantarctic Front positions are subject to strong and spatially inhomogeneous variability. Topography constrains the frontal variability in the Southern Ocean as found in previous studies (e.g., Gordon et al. 1978; Chelton et al. 1990; Gille 1994; Moore et al. 1999; Sokolov and Rintoul 2008; Dong et al. 2006). Steep bottom slopes are associated with very weak variations of the front position, whereas flat-bottom areas are subject to large movement of the fronts (Figs. $9 \mathrm{a}, 10 \mathrm{a})$. The variability of the jet intensity is shown on the panels (Figs. 9b, 10b), which represent the frequency of occurrence of a particular SSH gradient at each longitude. Topography influences not only the front's position but also its intensity. Figures 9c, 10c show the depth of the bathymetry along the pathway of the fronts; the ACC must negotiate a number of large topographic barriers, and the meridional deflection of the current influences its structure and variability.

Along the ACC pathway, we can define three categories of flow for the SAF and the PF. These are merging, shoaling, and strong meandering in the wake or the lee of topographic obstacles.

\section{1) Merging}

When the flow is steered around major topographic structures but is not forced to pass over them, the two fronts converge, their spatial variability is reduced, and their intensity strongly increases (Figs. 9, 10). These major topographic features are associated with stronger large-scale potential vorticity $(\mathrm{f} / \mathrm{h})$ gradients, which impose a stronger constraint on the flow and induce the merging of the different branches of the ACC into fewer but more intense jets. This is observed at the Kerguelen Plateau for the SAF, around the bathymetry south of Crozet Island at $40^{\circ} \mathrm{E}$ for the PF, around the Campbell Plateau at $170^{\circ} \mathrm{E}$, and across the Eltanin Fracture Zone.

\section{2) SHOALing}

When a jet is constrained to pass over a shallow plateau or ridge, the intensity of the flow decreases and the 
Western Indian Kerguelen Eastern IndianSouth East Macquarie Eltanin South Atlantic

a)

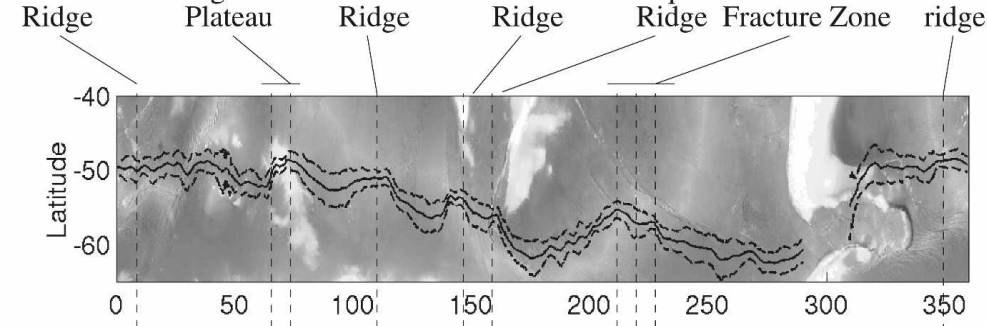

b)

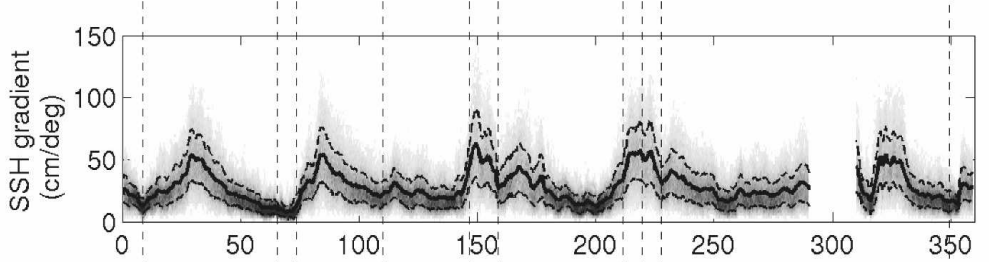

c)

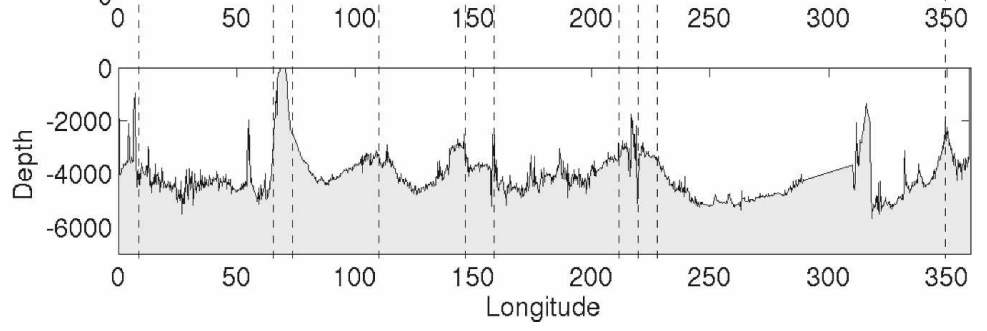

FIG. 9. (a) Map of bottom topography in the Southern Ocean with the mean PF position superimposed (solid line black); the dashed line represents the two std dev envelopes around the mean PF position. (b) The frequency of occurrence of SSH gradients at the PF position, as a measure of the front intensity at each longitude. Colors range from black (often) to white (rare). Also marked are the mean SSH gradients at each longitude (solid black) and the two std dev limit (dashed line). (c) Depth of the bathymetry along the mean PF pathway.

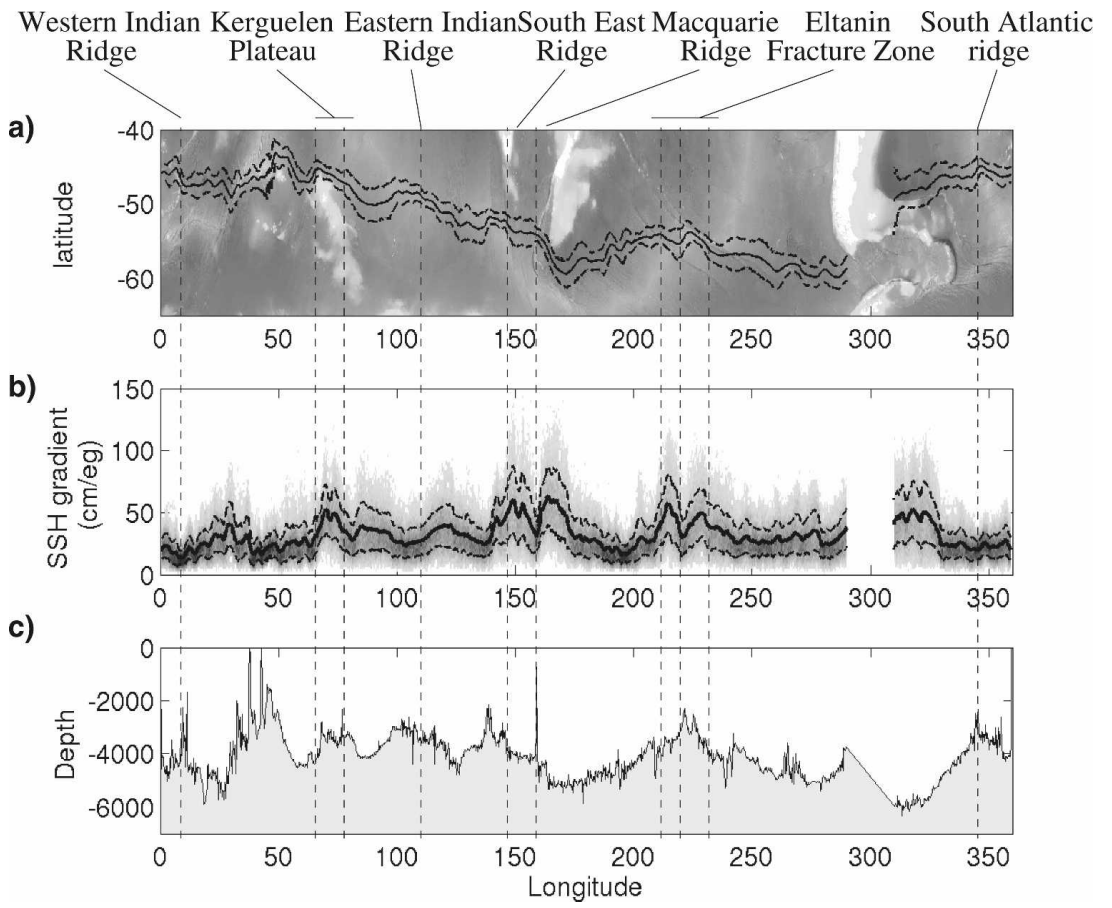

FIG. 10. Same as Fig. 9, but for the SAF. 
front tends to move equatorward to compensate for its loss of potential vorticity. In most cases, fractures or valleys exist in the bathymetric structure, creating a fixed pathway for the flow. This explains the weak spatial variability observed. This occurs at the western Indian Ocean Ridge, at the Crozet Plateau for the SAF, at the Kerguelen Plateau for the PF, at the southeastern Indian Ridge, at the Macquarie Ridge, in the middle of the Eltanin Fracture Zone, between the two fractures, and above the South Atlantic Midocean Ridge (Figs. 9, $10)$. The drop in variability over shallow plateaus is well documented in numerical models (e.g., Treguier and Mc Williams 1990) and altimetric studies (Sandwell and Zhang 1989; Morrow et al. 1994). Wilkin and Morrow (1994) have also shown that kinetic energy above sharp topography is transferred from the turbulent (EKE) to the mean (MKE) component resulting in a more stable flow.

\section{3) LEE EFFECT}

Downstream of strong topographical constraints, as $\mathrm{f} / \mathrm{h}$ gradients become weaker, the current becomes much more variable in space and the fronts split. At least three areas show this behavior clearly: downstream of Kerguelen Plateau, downstream of the Campbell Plateau, and downstream of the Pacific midocean ridge fracture zones. In these areas of variable current, the intensity remains strong. So although the jet's position is highly variable, with strong meanders, it is generally still a coherent jet.

In areas where the fronts are subject to strong spatial variability and can be shifted by a few degrees latitude from their mean pathway, we aim to establish whether their changing position is driven by atmospheric forcing. A direct local dynamical relation between front position and wind stress curl would be surprising because the ocean response is expected to be partly driven by the net-integrated effect of forcing across a large region. Nevertheless, there may be a local correlation and we first investigate this possibility. A positive correlation is found between ACC fronts and zero-wind stress curl positions in the South Indian Basin and near Drake Passage (not shown). However, our results also show substantial longitudinal structure in the ocean response. A coherence analysis by Dong et al. (2006) suggests that meridional shifts of the PF correspond to meridional shifts of the wind field. Our regional variations differ from the results of Dong et al. (2006), probably because they focused on a zonal mean of their local coherence results. As noted earlier, if a significant direct link exists between the structure of the atmospheric forcing and the ACC system of fronts, then we expect to find it mainly through the SAM and ENSO climate modes. The observed SLA response to the atmospheric SAM and ENSO forcing shows a distinct regional pattern (Fig. 1b). Hence, we have divided the Southern Ocean into smaller basins to consider how the ACC fronts respond regionally to the atmospheric forcing.

\section{b. Indian sector: $40^{\circ}-110^{\circ} \mathrm{E}$}

Figures 9a, 10a have already shown the strong topographic influence of the Crozet Plateau and Kerguelen Plateau, constraining the flow in the Indian Basin. The SAF and PF show a strong variability downstream $\left(80^{\circ} \%\right.$ $100^{\circ} \mathrm{E}$ ) of the Kerguelen Plateau. Upstream of the plateau, the SAF is constrained by the Crozet Plateau, but the PF shows a more variable position. In these regions of strong variability, a regression of the SAF (Fig. 11a) and PF (Fig. 12a) shows a clear anticorrelation between the front position and the SAM. The fronts are shifted to the south (north) during positive (negative) SAM events. For the SAF, this occurs downstream of the Kerguelen Plateau between $80^{\circ}$ and $110^{\circ}$ E. For the PF, it occurs upstream and downstream of the plateau, with no significant relationship as the front traverses the Kerguelen Plateau. No significant influence of ENSO is observed in the Indian sector.

Figures $11 b, c, 12 b, c$ show that the strong covariances around Kerguelen are dominated by the highfrequency band (less than 3 months), with almost no significant covariance observed in the low-frequency band (greater than $1 \mathrm{yr}$ ). SAM explains up to $20 \%$ of the high-frequency movement of the SAF and PF. Thus, in the Indian sector, it is mainly the highfrequency positive SAM events that are associated with a southward meandering of the front, in line with the southward shift of the maximum wind stress.

\section{c. Indo-Pacific sector: $110^{\circ}-220^{\circ} \mathrm{E}$}

In the Indo-Pacific sector, frontal movements are very different than those observed in the Indian Basin. The regression of the front position on the indices shows that the high-frequency frontal response is much weaker (Figs. 11b, 12b). However, at low frequencies, a positive ENSO event is associated with a statistically significant southward movement of the fronts (especially for the Polar Front). The ENSO index explains up to $40 \%$ of the low-frequency movement of the fronts with a correlation of approximately -0.5 . Positive SAM is associated with a weak northward frontal movement.

In this sector, negative ENSO events and positive SAM events are also associated with a southward 

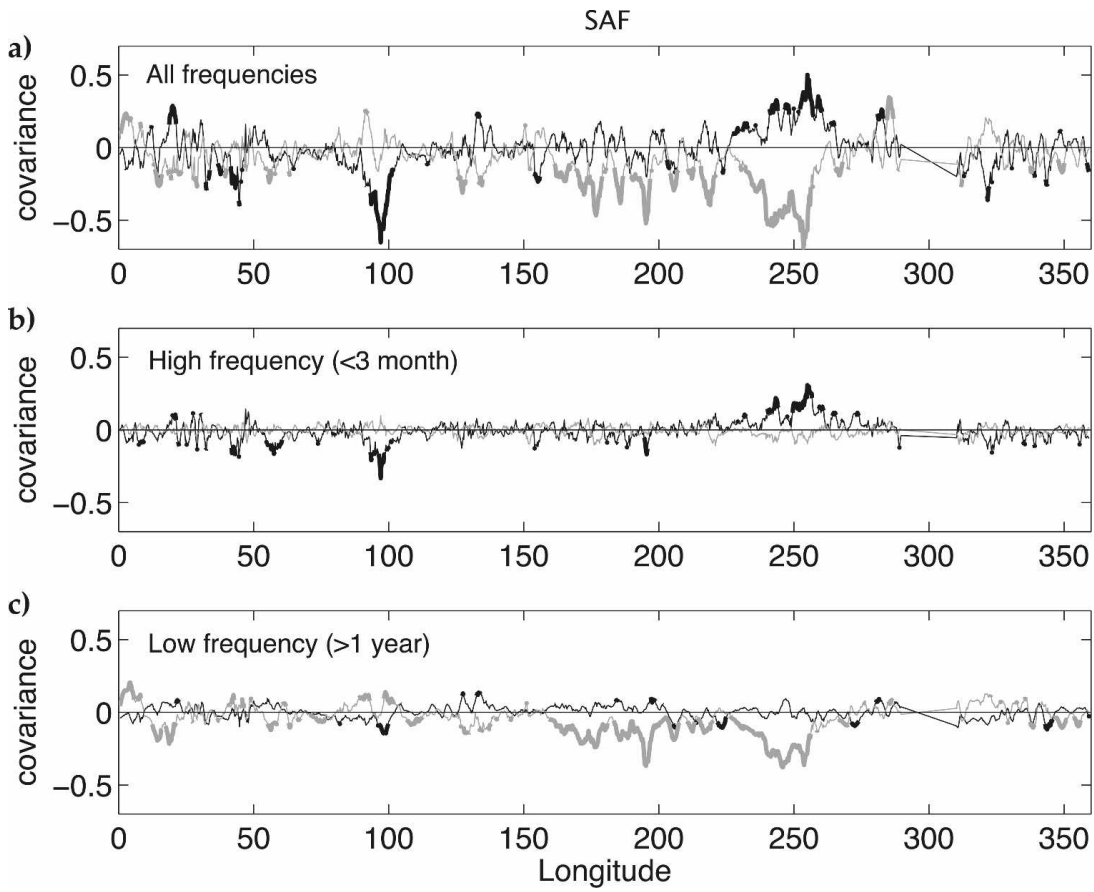

FIG. 11. (a) Covariance of the meridional position of the SAF with the SAM (black) or ENSO (gray) indexes as a function of longitude. Boldface line shows values above the $95 \%$ confidence level. (b) Same as (a), but for the high-frequency band (less than 3 months). (c) Same as (a), but for the low-frequency band (more than $1 \mathrm{yr}$ ).
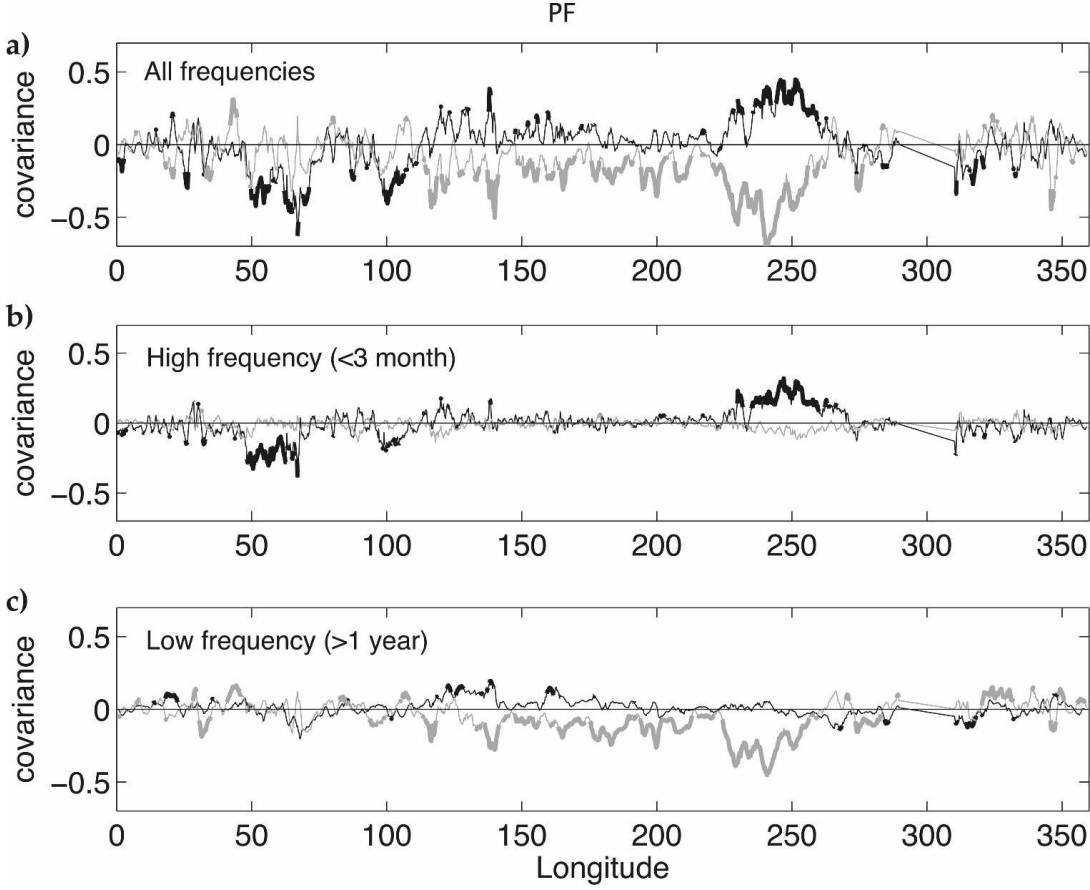

FIG. 12. (a) Covariance of the meridional position of the PF and the SAM (black) or ENSO (gray) indexes as a function of the longitude. Boldface line shows a significance above the $95 \%$ confidence level. (b) Same as (a), but for the high-frequency band of the signal (less than 3 months). (c) Same as (a), but for the low- frequency band of the signal (more than $1 \mathrm{yr}$ ). 
anomaly of the zero-stress curl position (not shown). For positive SAM events, the atmospheric circulation shows a southward shift in maximum winds or strengthened westerlies to the south as described by Thompson and Wallace (2000). Then, one might predict an associated southward intensification of the oceanic jet (as in Hall and Visbeck 2002; Sen Gupta and England 2006). However, we observe the opposite phenomena. The frontal movements are dominated by a lower-frequency response, which may be due to a nonlocal wind response. We also note that nonlocal forcing can generate a response after some lag. Indeed, a slightly better correlation, barely significant, with the SAM is obtained at a 4-month lag in this region. This may represent an adjustment time to a lower-frequency variability of the SAM.

\section{d. Eastern Pacific sector: $220^{\circ}-290^{\circ} \mathrm{E}$}

The eastern Pacific sector, downstream of the Pacific Midocean Ridge, shows a strong response to both ENSO and SAM, which is time dependent. There is a clear relation between the frontal movement and the ENSO index at low frequencies (Figs. 11c, 12c). Positive ENSO events are associated with a poleward frontal displacement, and this index explains about $50 \%$ of the low-frequency frontal variability variance. However, these plots also depict a significant high-frequency response of the fronts to the SAM forcing. Positive SAM events tend to push the fronts to the north, and SAM explains more than $20 \%$ of the high-frequency frontal variance. Interestingly, we have the same lowfrequency frontal response to ENSO in the Indo-Pacific and central Pacific, with negative ENSO events leading to an equatorward movement of the fronts. However, the high-frequency frontal response to positive SAM events is equatorward in the eastern Pacific, whereas it is poleward around Kerguelen in the Indian sector. In the following section, we will consider why this is so.

\section{Mechanisms controlling the observed variability}

The longitudinal structure of the ACC is controlled at first order by the bottom topography. However, in flat-bottom regions, the position of the fronts is more variable and can be influenced by mesoscale activity or atmospheric forcing. We have shown in the previous section that the atmospheric variability of the Southern Ocean represented by the SAM and ENSO climate modes can act to shift the ACC jet from its mean position and that this variability is accentuated in flatbottom areas. In addition, the ACC, steered by topog- raphy, experiences large meridional excursions and exposes itself to different Ekman regimes. Even if the wind variations were entirely zonal, this effect would induce zonal asymmetry. Here, we consider the circumpolar evolution of the response in relation to realistic Ekman pumping and offer schematic models of the response in the different regions.

Previous studies have described a zonal ocean response to positive SAM events as follows (see, e.g., Sen Gupta and England 2006): (i) the increase of westerly wind intensity around $60^{\circ} \mathrm{S}$ implies a northward Ekman transport anomaly, while the easterly wind intensification around $40^{\circ} \mathrm{S}$ creates a poleward Ekman anomaly; (ii) Ekman convergence occurs between these two areas and causes increased downwelling around $45^{\circ}-55^{\circ} \mathrm{S}$, and the divergence created south of $60^{\circ} \mathrm{S}$ (due to the Antarctic continent) causes increased upwelling near the continent; (iii) the 3D Ekman circulation induces movement of the isopycnals, and consequently a zonal barotropic current is created by geostrophic adjustment. This generates an intensification of the westward current to the south (around $60^{\circ} \mathrm{S}$ ) and a deceleration of the current to the north (around $40^{\circ} \mathrm{S}$ ).

Section 3 has shown that although both the SAM and ENSO climate modes influence the front position, each index generates a different response depending on frequency and location. The relationship between the front position and the SAM is dominated by a highfrequency response (periods shorter than 3 months), whereas the frontal response to the ENSO forcing is at low frequency (periods greater than one year). In the Indo-Pacific and central Pacific Oceans, a positive ENSO event is associated with a low-frequency southward movement of the fronts. Figure $13 \mathrm{~b}$ shows that such an event is associated with a decrease of the westerlies in the whole Indo-Pacific basin, as noted by Karoly (1989). Investigating the mechanisms associated with this low-frequency response would require a much longer observational time series than that currently available with altimetry data, but they could be investigated in the future. We note that the first mode of the detrended low-pass-filtered SSH in the Southern Ocean is highly dominated by ENSO (not shown).

Hereafter, we will focus on the mechanisms controlling the high-frequency relationship between the SAM variability and frontal movements. A regression of the high-frequency part of the zonal wind stress on the SAM index reveals a strong zonal pattern with an intensification of the westerlies (Fig. 13a). However, when the fronts are superimposed, some regional differences appear. Although the wind anomaly pattern is quite zonal (Fig. 13a), the relative position of the fronts 
a)

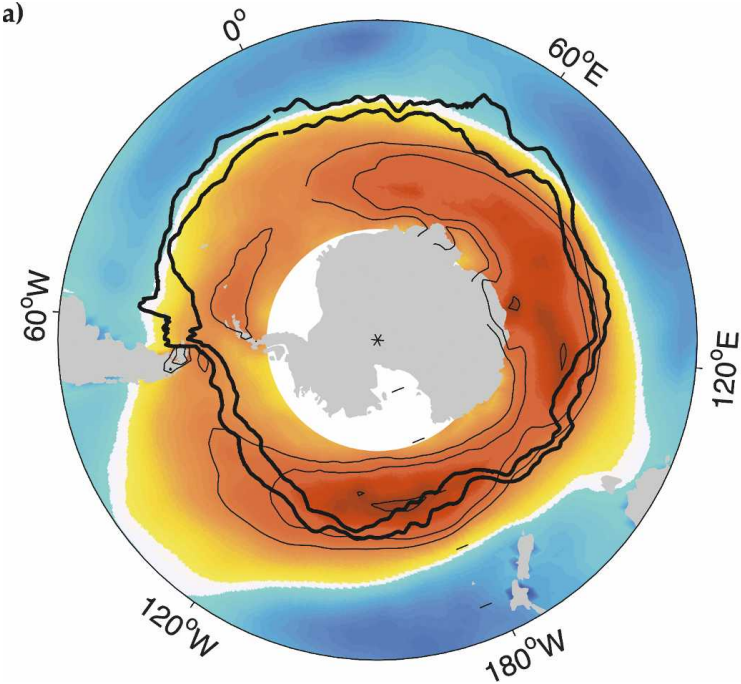

b)

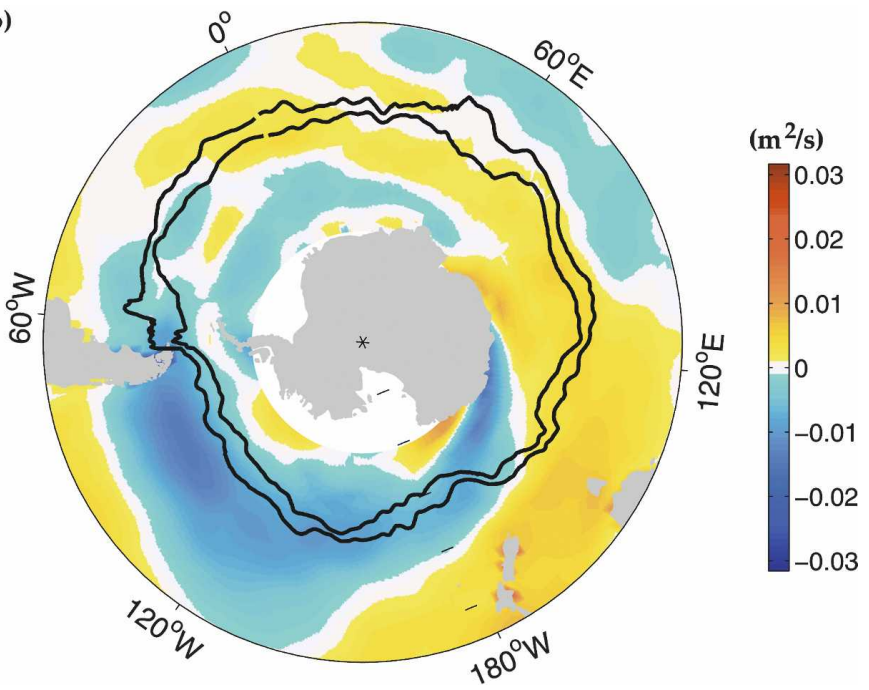

FIG. 13. (a) High-frequency component (less than 3 months) of the meridional Ekman transport anomaly regressed onto the SAM index. (b) Low-frequency component (more than $1 \mathrm{yr}$ ) of the meridional Ekman transport anomaly regressed onto the (right) ENSO index.

with respect to the maximum in wind intensification introduces different regional oceanic responses.

To better understand the regional ocean response, we propose three schematic descriptions of the frontal response to the high-frequency Ekman transport anomalies.

\section{a. The Indian-Atlantic case}

The SAM events tend to dominate the sea level response, and the maximum in northward Ekman transport intensification occurs south of the fronts. North of the fronts, we observe either a weaker northward anomaly of Ekman transport or a southward anomaly. The resulting Ekman convergence north of the intensification causes increased downwelling anomalies, both north and south of the fronts. In this region of the ocean, the ACC flows at latitudes near $45^{\circ} \mathrm{S}$; hence the Antarctic continent is ignored. The downwelling over the whole region north of the ACC can contribute to the positive SLA pattern observed in Fig. 1b. The downwelling also increases the slope of the isopycnals, causing a strong intensification of the flow and a baroclinic displacement of the upper front to the south, via geostrophic adjustment. This phenomenon has been observed previously in realistic coupled models and is capable of shifting the circulation (Hall and Visbeck 2002; Sen Gupta and England 2006). This is summarized in the schematic in Fig. 14a, which agrees with the observations of frontal movements described in section 3b, and Figs. 11b, $12 b$.

\section{b. The Indo-Pacific case}

A tongue of maximum equatorward Ekman transport intensification occurs in the Indo-Pacific region between $110^{\circ} \mathrm{E}$ and $140^{\circ} \mathrm{W}$. The Campbell Plateau south of New Zealand blocks the whole ACC system of fronts, steering them farther south into the maximum equatorward Ekman transport anomaly. Ekman pumping anomalies are thus centered on the fronts. Divergence occurs to the south, whereas a convergence is induced to the north. In terms of sea level anomalies, the upwelling to the south of the fronts is associated with a negative SLA, and the downwelling to the north of the front with a positive SLA (Fig. 1b). In the idealized case in which the anomalous upwelling and downwelling are symmetric across the front, the front would remain in the same position but the slope of the isopycnals would increase, intensifying the nearsurface current. This scenario is summarized in Fig. 14b and is consistent with the observed lack of high-frequency frontal movements revealed in section $3 \mathrm{c}$ and Figs. 11b, 12b.

\section{c. The Pacific case}

In the Pacific, the SLP pattern associated with the SAM mode shows an equatorward extension of its low pressure cell in the Pacific, creating a large nonsymmetric pattern in this area $\left(220^{\circ}-300^{\circ} \mathrm{E}\right.$; see Fig. 1a). Around the circumpolar belt, this is the primary asymmetric of the low pressure pattern of SLP associated with SAM. Lachlan-Cope et al. (2001) explained the 
a)

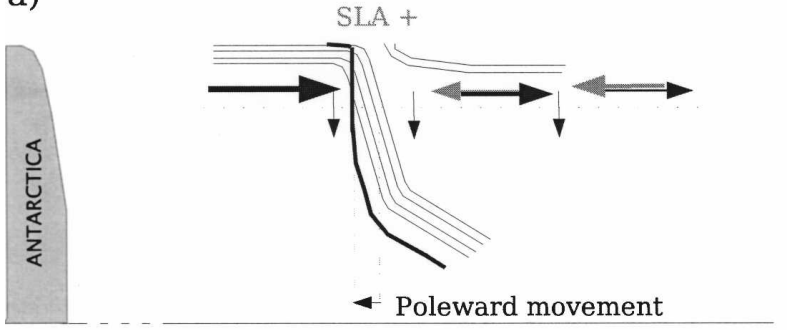

b)

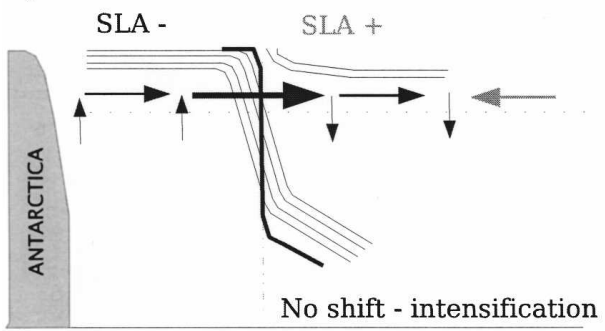

c)

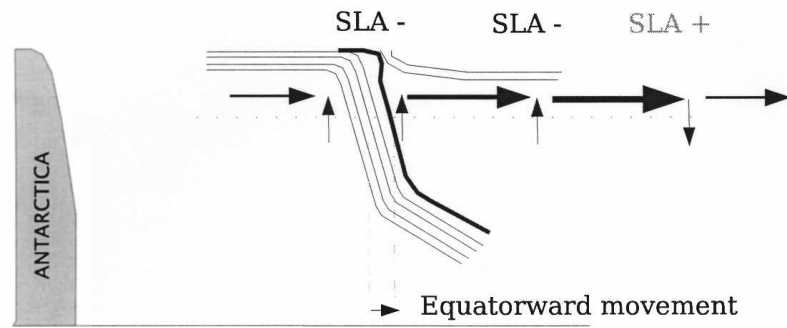

FIG. 14. Schematic of the different scenarios observed in the Southern Ocean during positive SAM events for the (a) typical Indian Ocean case, (b) Indo-Pacific case, and (c) central Pacific case. Black and gray arrows represent the Ekman transport anomalies. Their intensity is shown by the thickness of the line. Vertical black arrows show the vertical Ekman velocity anomaly. Thin black lines are the isopycnals in their mean frontal position, whereas the thick black vertical line represents the typical isopycnal response to the positive SAM event. The horizontal dotted line represents the base of the Ekman layer.

SLP response to the SAM asymmetry by demonstrating a sensitivity in the strength of this low pressure anomaly to the zonal asymmetry of the Antarctic landmass distribution. This induces a wind anomaly farther north than anywhere else in this region during positive SAM events. In addition, the topography forces the mean position of the fronts to pass farther south through the Pacific Midocean Ridge Fracture Zones near $55^{\circ} \mathrm{S}$ and through Drake Passage (from $-55^{\circ}$ to $-60^{\circ} \mathrm{S}$ ), implying a mean position of the fronts farther south. Thus, in the Pacific, the maximum intensification of the northward Ekman transport occurs far to the north of the fronts. Consequently, upwelling occurs over the whole region surrounding the fronts. This can explain the large northward extension of negative SLA (Fig. 1b). The colder, fresher water and denser water being transported by the Ekman currents shift the isopycnals to the north. This alteration of the isopycnal gradient will propagate to the interior by geostrophic adjustment. Again, this type of dynamical process has been previously observed in a realistic coupled model in response to atmospheric variability (Hall and Visbeck 2002; Sen Gupta and England 2006). The schematic shown in Fig. $14 \mathrm{c}$ summarizes this scenario and, again, is consistent with the description of the frontal movements shown in section $3 d$ and Figs. 9b, 10b.

The dynamical mechanisms explained by these simplified schematics focus on the processes that will act on the fronts and their associated vertical isopycnals. Our simple dynamical arguments are based on the varying strength of the regions of convergence-divergence of the surface and subsurface density field and follow on the same line as previous, more complex, and detailed coupled model studies on these issues (Hall and Visbeck 2002; Sen Gupta and England 2006).

The crux of our study is in revealing how the position of these zones of maximum convergence-divergence varies regionally with respect to the mean axis of the fronts. We note that these regional movements of the jet are qualitatively consistent with a simple zonal acceleration model forced by the typical wind pattern observed during a positive SAM event (not shown). A more detailed analysis of the dynamics of these mechanisms is needed to complete this first observational approach and will be investigated in the future using a realistic numerical model. Finally, we note that the impact of these atmospheric climate modes is not restricted to the frontal region. Figure $1 \mathrm{~b}$ clearly shows that SAM has a large-scale impact on the ocean, whereas we have mainly focused on its forcing of the frontal structure. The subsurface hydrographic evolution has been investigated at $140^{\circ} \mathrm{E}$ and shows a largescale sea level response to SAM and ENSO over the same period (Morrow et al. 2008) as well as weak frontal shifts, as described in the Indo-Pacific case.

\section{Conclusions}

The position and variability of the two main fronts of the ACC have been determined using a combination of altimetric and hydrographic data. Argo profiles are very important in the representation of the subsurface ocean. They provide more than $50 \%$ of the total historical profiles deeper than $1500 \mathrm{~m}$ that contribute to our finer-resolution mean sea surface height field. We have extended the method developed by Sokolov and Rintoul (2002) for the region south of Australia to the 
circumpolar Southern Ocean, and we have identified the SAF and the PF with a particular SSH contour. Detailed comparisons of these front positions with hydrographic data support the identification of these two principal ACC fronts in this fashion. It is not clear if additional circumpolar fronts may be identified in this way. The great advantage of this method is to provide a robust way to monitor the frontal variability over the entire circumpolar path for more than $13 \mathrm{yr}$.

Fronts are strongly steered by the topography. We found three typical frontal regimes: merging, shoaling, and lee meandering, depending on their position relative to the bathymetry. Thus, topography influences the pathway of the fronts as seen in previous studies (e.g., Gordon et al. 1978; Chelton et al. 1990; Gille 1994; Moore et al. 1999; Sokolov and Rintoul 2008; Dong et al. 2006), but also influences the mean intensity of the jet. In nearly flat-bottom areas, fronts are especially subject to large meandering due to mesoscale activity and atmospheric forcing.

We have investigated the role of atmospheric forcing, considering the two most important modes of variability in the Southern Hemisphere, the SAM and ENSO. We found that both ENSO and SAM produce a substantial oceanic response but in different spectral windows. SAM tends to dominate the high-frequency band (less than 3 months), whereas ENSO dominates the low-frequency band (more than $1 \mathrm{yr}$ ), especially in the Pacific region. We note that there is still a weak lowfrequency SAM response in the Indo-Pacific. We found that although the SAM is the dominant mode of atmospheric variability in the Southern Hemisphere and has a large degree of zonal symmetry, the high-frequency oceanic response to this mode, including the movement of the ACC fronts, shows strong regional differences. This is partly because the fronts, steered by the topography, traverse different latitudes around the circumpolar belt and are exposed to different Ekman regimes.

Instead of a zonally uniform response of the ACC to the atmospheric forcing, we have proposed three typical scenarios depending on which Ekman regime the fronts cross. For example, during positive SAM events, the response in the Indian Ocean is a poleward frontal movement, whereas in the Pacific the movement is equatorward. In the Indo-Pacific, the fronts are intensified with no distinct meridional shift. These scenarios agree with the observed reaction of the fronts and are consistent with the observed SLA response to the atmospheric forcing. Note that these scenarios are based on a negative correlation between the temporal derivative of the SLA and the vertical Ekman velocity (i.e., upwelling is associated with a decrease of the SLA). We indeed observe this correlation with essentially no spatial pattern in the Southern Ocean (not shown).

The shifting of these ACC fronts in response to the climate mode forcing may invoke a local feedback onto the atmospheric circulation (Chelton et al. 2004), which warrants further investigation. In addition, the position of the SAF provides the natural southern boundary limiting the water mass properties of Subantarctic Mode Waters, formed in the deep winter mixed layers directly north of the fronts (e.g., Hanawa and Talley 2001). These waters have been observed to freshen in recent decades. This freshening is thought to be due to the mean Ekman advection of fresher surface water from farther south (Wong et al. 1999; Aoki et al. 2005). Thus, cross-frontal exchange of cool freshwater is important in setting their water mass characteristics, and frontal fluxes have been shown to be key in setting up the deep mode water formation area in the southeastern Indian Ocean (Sallée et al. 2006). Whether the direct impact of atmospheric modes on SST and on air-sea fluxes over mode waters outweighs their indirect effect via anomalous advection or variable cross-frontal exchange is an important question to resolve.

Acknowledgments. The Argo data were collected and made freely available by the international Argo project and the national programs that contribute to it (http:// www.argo.ucsd.edu; http://argo.jcommops.org). Argo is a pilot program of the Global Ocean Observing System. We thank the SURVOSTRAL/WOCE SR3 project for providing corrected section data south of Australia, and Nicolas Metzl for the OISO hydrographic data collected near Kerguelen Island. KGS received support from NSF OCE-0336697 and the Laboratoire d' Etudes en Geophysique et Oceanographie Spatiale. Funding for this study comes from the French PATOM and TOSCA programs.

\section{REFERENCES}

Aoki, S., N. Bindoff, and J. Church, 2005: Interdecadal water mass changes in the Southern Ocean between $30^{\circ} \mathrm{E}$ and $160^{\circ} \mathrm{E}$. Geophys. Res. Lett., 32, L07607, doi:10.1029/2004GL022220.

Baker, D. J., 1982: A note on Sverdrup balance in the Southern Ocean. J. Mar. Res., 40 (Suppl.), 21-26.

Belkin, I. M., and A. L. Gordon, 1996: Southern Ocean fronts from the Greenwich Meridian to Tasmania. J. Geophys. Res., 101, 3675-3696.

Chelton, D. B., M. Schlax, D. Witter, and J. Richmann, 1990: Geosat altimeter observations of the circulation of the Southern Ocean. J. Geophys. Res., 95, 17 877-17 903.

,,-- M. Freilich, and R. Millif, 2004: Satellite measurements reveal persistent small-scale features in ocean winds. Science, 303, 978-983.

Deacon, G., 1937: The hydrology of the Southern Ocean. Discovery Rep., XV, 1-124. 
Dong, S., J. Sprintall, and S. T. Gille, 2006: Location of the Antarctic polar front from AMSR-E satellite sea surface temperature measurements. J. Phys. Oceanogr., 36, 2075-2089.

Ducet, N., P. Le Traon, and G. Reverdin, 2000: Global highresolution mapping of ocean circulation from TOPEX/ Poseidon and ERS-1 and -2. J. Geophys. Res., 105, $19477-$ 19498.

Fu, L., 2003: Wind-forced intraseasonal sea level variability of the extratropical oceans. J. Phys. Oceanogr., 33, 436-449.

Fukumori, I., R. Raghunath, and L. Fu, 1998: Nature of the global large-scale sea level variability in relation to atmospheric forcing: A modeling study. J. Geophys. Res., 103, 5493-5512.

Gille, S. T., 1994: Mean sea surface height of the Antarctic Circumpolar Current from Geosat data: Method and application. J. Geophys. Res., 99, 18 255-18 273.

— D. P. Stevens, R. T. Tokmakian, and K. J. Heywood, 2001: Antarctic Circumpolar Current response to zonally averaged winds. J. Geophys. Res., 106, 2743-2759.

Gordon, A. L., E. Molinelli, and T. Baker, 1978: Large-scale relative topography of the Southern Ocean. J. Geophys. Res., 83, 3023-3032.

Hall, A., and M. Visbeck, 2002: Synchronous variability in the Southern Hemisphere atmosphere, sea ice, and ocean resulting from the annular mode. J. Climate, 15, 3043-3057.

Hanawa, K., and L. Talley, 2001: Mode waters. Ocean circulation and climate: Observing and Modeling the Global Ocean, G. Siedler, J. Church, and J. Gould, Eds., International Geophysics Series, Vol. 77, Academic Press, 373-393.

Hoskins, B., and D. Karoly, 1981: The steady linear response of a spherical atmosphere to thermal and orographic forcing. $J$. Atmos. Sci., 38, 1179-1196.

Hughes, C. W., and E. Ash, 2001: Eddy forcing of the mean flow in the Southern Ocean. J. Geophys. Res., 106, 2713-2722.

—, M. Meredith, and K. Heywood, 1999: Wind-driven transport fluctuations through Drake Passage: A southern mode. $J$. Phys. Oceanogr., 29, 1971-1992.

Karoly, D., 1989: Southern Hemisphere circulation features associated with El Niño-Southern Oscillation events. J. Climate, 2, 1239-1252.

Kostianoy, A., A. Ginzburg, M. Frankignoulle, and B. Delille, 2004: Fronts in the Southern Indian Ocean as inferred from satellite sea surface sea temperature data. J. Mar. Res., 45, 55-73

Lachlan-Cope, T., W. Connoley, and J. Turner, 2001: The role of the non-axisymmetric Antarctic orography in forcing the observed pattern of variability of the Antarctic climate. Geophys. Res. Lett., 28, 4111-4114.

Le Traon, P., F. Nadal, and N. Ducet, 1998: An improved mapping method of multisatellite altimeter data. J. Atmos. Oceanic Technol., 15, 522-534.

Lombard, A., A. Cazenave, P. Le Traon, S. Guinehut, and C. Cabanes, 2006: Perspectives on present-day sea level change: A tribute to Christian le Provost. Ocean Dyn., 56, 445-451.

Moore, J., M. Abbott, and J. Richman, 1999: Location and dynamics of the Antarctic polar front from satellite sea surface temperature data. J. Geophys. Res., 104, 3059-3073.

Morrow, R., R. Coleman, J. Church, and D. Chelton, 1994: Surface eddy momentum flux and velocity variances in the Southern Ocean from Geosat altimetry. J. Phys. Oceanogr., 24, 2050-2071.

_ A. Brut, and A. Chaigneau, 2003: Seasonal and interannual variations of the upper ocean energetics between Tasmania and Antarctica. Deep-Sea Res. II, 50, 339-356.

_, G. Valladeau, and J. Sallee, 2008: Observed subsurface signature of Southern Ocean decadal sea level rise. Prog. Oceanogr., in press.

Nowlin, W., T. Whitworth III, and R. Phillsbury, 1977: Structure and transport of the Antarctic Circumpolar Current at Drake Passage from short-term measurements. J. Phys. Oceanogr., 7, 788-802.

Orsi, A., T. Whitworth III, and W. Nowlin Jr., 1995: On the meridional extent and fronts of the Antarctic Circumpolar Current. Deep-Sea Res. II, 42, 641-673.

Park, Y.-H., E. Charriaud, and M. Fieux, 1998: Thermohaline structure of the Antarctic surface water/winter in the Indian sector of the Southern Ocean. J. Mar. Res., 17, 5-23.

Peterson, R. G., and L. Stramma, 1991: Upper-level circulation in the South Atlantic Ocean. Prog. Oceanogr., 26, 1-73.

Qiu, B., 2002: Large-scale variability in the midlatitude subtropical and subpolar North Pacific Ocean: Observations and causes. J. Phys. Oceanogr., 32, 353-375.

Ridgway, K. R., J. R. Dunn, and J. L. Wilkin, 2002: Ocean interpolation by four-dimensional weighted least squaresApplication to the waters around Australasia. J. Atmos. Oceanic Technol., 19, 1357-1375.

Rintoul, S. R., and S. Sokolov, 2001: Baroclinic transport variability of the Antarctic Circumpolar Current south of Australia (WOCE repeat section SR3). J. Geophys. Res., 106, 28152832.

Rio, M.-H., P. Schaeffer, F. Hernandez, and J.-M. Lemoine, 2005: Estimation of the global mean dynamic topography through the combination of altimetric data, in-situ measurements and GRACE geoid: From global to regional studies. Proc. Int. GOCINA Workshop, Luxembourg.

Roemmich, D. J. Gilson, R. Davis, P. Sutton, S. Wijffels, and S. Riser, 2007: Decadal spinup of the South Pacific subtropical gyre. J. Phys. Oceanogr., 37, 162-173.

Sallée, J., N. Wienders, R. Morrow, and K. Speer, 2006: Formation of subantarctic mode water in the southeastern Indian Ocean. Ocean Dyn., 56, 525-542.

Sandwell, D. T., and B. Zhang, 1989: Global mesoscale variability from the Geosat exact repeat mission: Correlation with ocean depth. J. Geophys. Res., 94, 17 971-17984.

Sen Gupta, A., and M. England, 2006: Coupled oceanatmosphere-ice response to variations in the Southern Annular Mode. J. Climate, 19, 4457-4486.

Sokolov, S., and S. R. Rintoul, 2002: Structure of Southern Ocean fronts at $140^{\circ}$ E. J. Mar. Syst., 37, 151-184.

—, and 2007: Multiple jets of the Antarctic Circumpolar Current south of Australia. J. Phys. Oceanogr., 37, 13941412.

Stammer, D., 1997: Steric and wind-induced changes in TOPEX/ POSEIDON large-scale sea surface topography observations. J. Geophys. Res., 102, 20 987-21 009.

Sun, C., and D. R. Watts, 2001: A circumpolar gravest empirical mode for the Southern Ocean hydrography. J. Geophys. Res., 106, 2833-2856.

Thompson, D. W. J., and J. M. Wallace, 2000: Annular modes in the extratropical circulation. Part I: Month-to-month variability. J. Climate, 13, 1000-1016.

Treguier, A. M., and J. C. McWilliams, 1990: Topographic influences on wind-driven, stratified flow in a B-plane channel: An idealized model for the Antarctic Circumpolar Current. $J$. Phys. Oceanogr., 20, 321-343. 
Turner, J., 2004: The El Niño-Southern Oscillation and Antarctica. Int. J. Climatol., 24, 1-31.

Vivier, F., K. Kelly, and M. Harismendy, 2005: Causes of largescale sea level variations in the Southern Ocean: Analyses of sea level and a barotropic model. J. Geophys. Res., 110, C09014, doi:10.1029/2004JC002773.

Warren, B. A., J. H., LaCasce, and P. E. Robbins, 1996: On the obscurantist physics of "form drag" in theorizing about the Circumpolar Current. J. Phys. Oceanogr., 26, 2297-2301.

Watts, D. R., C. Sun, and S. R. Rintoul, 2001: A two-dimentional gravest empirical modes determined from hydrographic ob- servations in the Subantarctic Front. J. Phys. Oceanogr., 31, 2186-2209.

Webb, D., and B. de Cuevas, 2002: An ocean resonance in the Indian sector of the Southern Ocean. Geophys. Res. Lett., 29, 1664, doi:10.1029/2002GL015270.

Wilkin, J., and R. Morrow, 1994: Eddy kinetic energy and momentum flux in the Southern Ocean: Comparison of a global eddy-resolving model with altimeter, drifter, and currentmeter data. J. Geophys. Res., 99, 7903-7916.

Wong, A. P. S., N. L. Bindoff, and J. A. Church, 1999: Large-scale freshening of intermediate waters in the Pacific and Indian Oceans. Nature, 400, 440-443. 